\title{
Investigation of riblet geometry and start locations of herringbone riblets on pressure losses in a linear cascade at low Reynolds numbers
}

DOI:

$10.1115 / 1.4046960$

\section{Document Version}

Accepted author manuscript

Link to publication record in Manchester Research Explorer

Citation for published version (APA):

Liu, Q., Zhong, S., \& Li, L. (2020). Investigation of riblet geometry and start locations of herringbone riblets on pressure losses in a linear cascade at low Reynolds numbers. Journal of Turbomachinery, 142(10), 1-20. https://doi.org/10.1115/1.4046960

\section{Published in:}

Journal of Turbomachinery

\section{Citing this paper}

Please note that where the full-text provided on Manchester Research Explorer is the Author Accepted Manuscript or Proof version this may differ from the final Published version. If citing, it is advised that you check and use the publisher's definitive version.

\section{General rights}

Copyright and moral rights for the publications made accessible in the Research Explorer are retained by the authors and/or other copyright owners and it is a condition of accessing publications that users recognise and abide by the legal requirements associated with these rights.

\section{Takedown policy}

If you believe that this document breaches copyright please refer to the University of Manchester's Takedown Procedures [http://man.ac.uk/04Y6Bo] or contact uml.scholarlycommunications@manchester.ac.uk providing relevant details, so we can investigate your claim.

\section{OPEN ACCESS}




\title{
Investigation of riblet geometry and start locations of herringbone riblets on pressure losses in a linear cascade at low Reynolds numbers
}

\author{
Qiang Liu ${ }^{\mathrm{a}}$, Shan Zhong ${ }^{\mathrm{a}, *}$, Lin $\mathrm{Li}^{\mathrm{a}}$ \\ ${ }^{a}$ School of Mechanical, Aerospace and Civil Engineering, Manchester University, \\ Manchester, M13 9PL, UK \\ * Corresponding author: shan.zhong@manchester.ac.uk
}

\section{Abstract}

In this paper, the effects of an array of herringbone riblets with different riblet geometry (height and spacing) and start locations on the pressure losses in a cascade of diffuser blades are investigated over a range of low Reynolds numbers $\left(0.50 \times 10^{5}-1.00 \times 10^{5}\right)$. The herringbone riblets with a given geometry are found to produce a profound modification to the wake structure above certain critical Reynolds numbers. It is also found that within the range of parameters tested an increase in riblet height and riblet spacing results in an onset of significant control effect at a lower Reynolds number, which is accompanied by a slight reduction in zone-averaged loss coefficient and flow turning angle. An upstream shift of the start position of the riblet array along the blades enables the riblets to become effective at a lower Reynolds number at the expense of a reduced loss reduction and flow turning angle. A semi-empirical relationship between the ratio of riblet height to local baseline boundary layer displacement thickness and the critical Reynolds number is established using the present experimental data. A preliminary methodology for designing the herringbone riblets to ensure an effective control of 2D flow separations around the mid-span of diffuser blades over a specified range of Reynolds numbers is also proposed.

\section{Introduction}

Compressors, such as those used in domestic appliances, operate at low Reynolds numbers within the range of $10^{4}$ to $10^{5}$ due to their small sizes. They tend to suffer from severe pressure losses due to laminar flow separation occurring on the suction surfaces of their blades. Efforts at optimising blade geometry are often hampered by inaccuracy of the models used for predicting laminar-to-turbulent transition. Therefore, further improvement in component efficiency and operating range would have to reply on successful implementation of suitable flow control methods that are capable of suppressing flow separation.

There is a large volume of research work aiming to control laminar flow separation using either active or passive flow control methods[1-3]. Methods, such as wall jets [4], plasma actuators [5] and vortex generators [6] are shown to be effective in delaying flow separation on turbine and compressor blades in laboratory experiments. Nevertheless, effective flow control methods, which are feasible to be implemented on small compressors and only impose a negligible amount of parasitic drag and modification to the blade profile, are still being sought.

Surface roughness is known to modify the flow characteristics in a near-wall region thus affecting boundary layer transition and flow separation. For example, randomly distributed roughness, such as sand grains, was shown to delay flow separation over aerofoils and compressor blades by triggering transition to turbulence [7]. However, randomly distributed roughness of given sizes could only lead to a reduction in the total drag on a given blade at specific flow conditions [8]. This limits the usefulness of this method in real settings where a gain in performance is expected over a range of Reynolds numbers.

Engineered roughness, whereby suitable manufacturing processes are optimized to generate variations in geometry and/or near-surface material properties to yield specific functions [9], has been explored as an attractive alternative. Longitudinal riblets, which were inspired by the surface patterns on sharks' skin, are a typical example of engineered surface roughness [10]. It was reported that a reduction of turbulent friction drag up to $10 \%$ could be achieved on a flat plate fitted with longitudinal riblets [11]. 
However, it was found that longitudinal riblets produced additional pressure losses if they were applied underneath a laminar flow region on a compressor blade (Lietmeyer et al. [12]). This is because due to the absence of near-wall turbulent streaks in a laminar boundary layer, the riblets act like unwanted surface roughness and produce a parasitic drag of their own. Hence longitudinal riblets are considered not suitable for laminar flow applications.

More recently, convergent-divergent riblets or herringbone riblets begin to attract research attention. In such riblet patterns, sections of left-tilted and right-tilted microgrooves are placed side by side in an alternating manner forming a spanwise array, see Figure 1a. The only difference between convergentdivergent riblets and herringbone riblets lies in that a small gap is left between the neighbouring riblet sections over the region where the converging line would be located (see Fig. 1b). These patterns are inspired by the micro-scale structures on the secondary flight feathers of birds $[13,14]$. Due to the directional orientation of the microgrooves, a spanwise surface flow is generated directing from the diverging line to the converging line [15]. To satisfy the continuity requirement, a weak large-scale secondary flow motion (also called roll mode) is generated within the boundary layer, resulting in an upwash over the diverging line and a downwash over the converging line (see Figure 1a). This secondary motion is found to profoundly modify the characteristics of the boundary layer in the spanwise direction [15-17].

Chen al. [14] reported a maximum friction drag reduction of $16 \%$ in a turbulent pipe flow when the inner surface of the pipe was covered by herringbone riblets with a riblet spacing of 20 viscous wall units. In contrast, the DNS simulations undertaken by Benschop and Breugem [18] reported a definite increase in turbulent friction drag. Therefore, at present there is no common consensus regarding the capability of herringbone riblets in reducing the surface friction drag in a turbulent boundary layer. Nevertheless, there is a compelling evidence that herringbone riblets are capable of producing a secondary motion in a boundary layer whether its state is laminar or turbulent [15-17]. Such secondary motion is expected to promote fluid mixing in the boundary layer, hence offering an effective mechanism for suppressing flow separation. In this study, it is the secondary flow motion that herringbone riblets generate in a boundary layer that is aimed to be harnessed for controlling the laminar flow separation over a compressor or diffuser blade for the first time, in the authors' opinion.

In 2017, the authors carried out an experiment to investigate the effect of herringbone riblets on the pressure loss in a linear cascade [19]. The experiment was performed on a set of diffuser blades with a high-turning angle $\left(\sim 60^{\circ}\right)$ at a Reynolds number of $1.00 \times 10^{5}$. A significant pressure loss reduction of $16.8 \%$ compared to the baseline case was obtained which was accompanied by an increase of $10^{\circ}$ in the flow turning angle. The velocity vectors leaving the cross-stream measurement plane also appeared to be more uniformly distributed, indicating that the extent of flow separation in the cascade has been reduced substantially.

Encouraged by these results, the authors conducted a detailed investigation on a set of diffuser blades with a turning angle of $22^{\circ}$. This work confirmed the effectiveness of herringbone riblets of a given geometry in separation control on the blades over a range of low Reynolds numbers and blade incidence angles [20]. The work presented in this paper reports a follow-on study aiming to examine the effectiveness of herringbone riblets of different micro-scale geometry and start locations along the blade in controlling flow separation at a fixed incidence angle over a range of Reynolds numbers. The finding from this work enables a semi-empirical relation for riblet height and riblet start location along the blade as a function of blade Reynolds number to be established for the first time. Such a correlation provides some insights about how the riblet geometry and the start position of a riblet array could be chosen to ensure an effective control of 2D flow separation around the mid-span of diffuser blades over a specified range of Reynolds numbers. 
a)

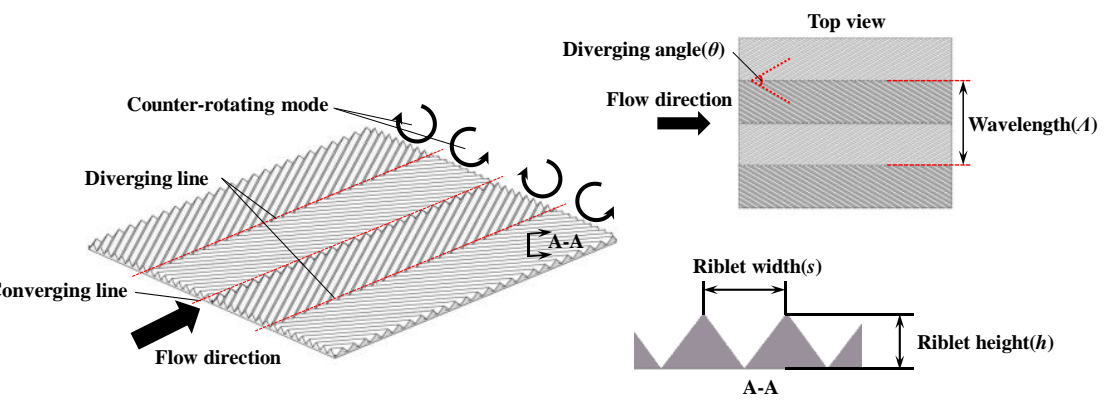

b)

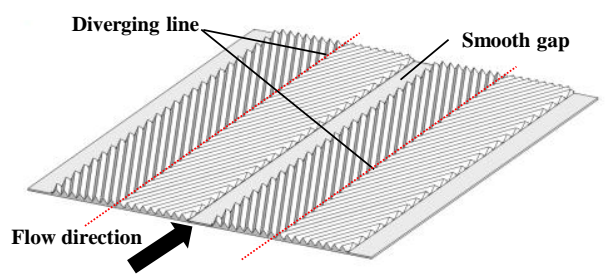

Figure 1 Schematics of a) convergent-divergent riblets and secondary flow motion that they produce; b) herringbone riblets with a constant height separated by a smooth gap similar to that proposed by Chen et al.[14].

\section{Experimental Facilities and Methods}

\subsection{The linear cascade}

All the experiments were carried out in a linear compressor cascade in the School of Mechanical, Aerospace and Civil Engineering, The University of Manchester. The cascade was made up of seven diffuser blades and two end-wall boards. The blade profile was extracted from the mid-span of a diffuser blade. The blades had an aspect ratio of 1.42 and a pitch of $0.9 c$ where $c$ is the blade chord length. The inlet metal angle and exit metal angle were $\beta_{1}=61^{\circ}$ and $\beta_{2}=39^{\circ}$, respectively, resulting in a blade turning angle of $\beta=22^{\circ}$ (See Figure 2a). The blade stagger angle is $54^{\circ}$. The Lieblein diffusion coefficient [21] based on the current experiments is estimated to be is between 0.47 and 0.56 .

In this setup, the incidence angle $(\alpha)$ of the blades (see Figure 2a) can be altered within the range of $10^{\circ}<\alpha<+10^{\circ}$ with the use of a set of interchangeable rectangular ducts with different exit angles located upstream of the inlet of the linear cascade. The level of flow uniformity at the cascade inlet has been checked. Both the surface oil flow viz patterns on the central five blades and the contours of pressure loss coefficient in the central four flow passages appear to be very similar. The turbulence intensity measured with a hot-wire probe traversing across the inlet of the central four passages also showed negligible differences. All these indicate a homogeneous inlet flow. More detailed description of this experimental facility can be found in Liu et al. [19].

a)

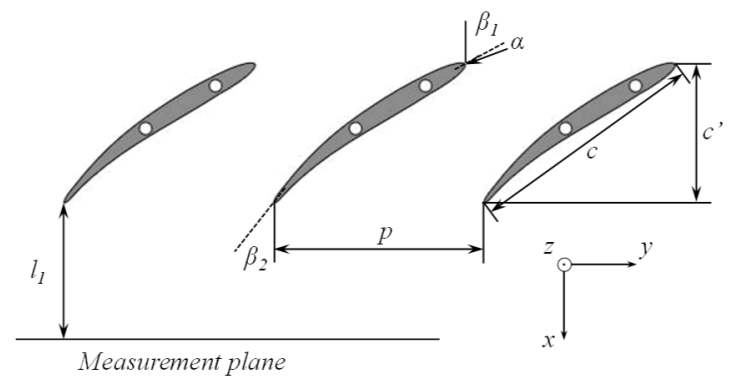

b)

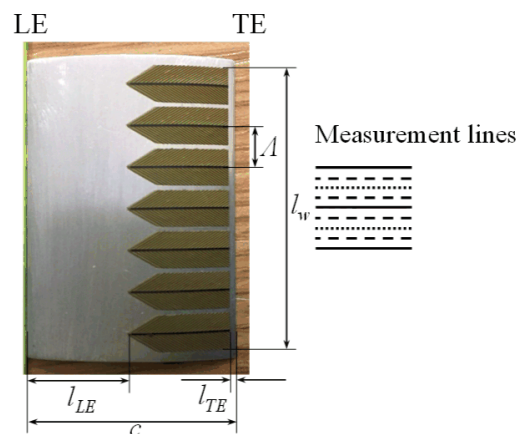

Figure 2 (a) Schematic drawing showing the location of measurement plane; (b) Layout of riblet foils on the blade surface and the measurement positions relative to the riblet foils along the blade span. 


\subsection{Herringbone riblets}

The herringbone riblets used in the experiments were manufactured on foils using advanced laser manufacturing techniques. An array of seven riblet foils was glued onto the blade suction surface as shown in Figure $2 \mathrm{~b}$. The leading edge of the array was aligned parallel to the leading edge of the blade. The riblet foil has a length $\left(l_{r}\right)$ of $0.49 c$ and a width $\left(b_{r}\right)$ of $0.173 c$. They were fixed along the blade span with a distance of $\Lambda=0.19 c$ between the centrelines of adjacent foils and a small gap between them. To ensure periodicity of the cascade flow, riblet foils were fixed on the suction surfaces of the five blades located in the middle of the cascade.

A schematic drawing of the herringbone riblets is given in Figure 3a. The yaw angle, $\theta$, that the grooves form with the centreline of the riblet foil is $30^{\circ}$, which is the same as that found on the secondary flight feathers of a wide range of bird species [14]. The riblet foils have an arrow-headed leading edge with an included angle of $60^{\circ}$. A slope was manufactured at the leading edge of each foil to minimize the influence of the finite thickness of the foils to the flow. A close-up view of the herringbone riblets together with the cross section of actual riblets shown in Figure $3 b$ reveals that the microscopic structure of individual riblets is well defined. The riblets are of high-quality manufacture, with a maximum uncertainty in depth of $7 \% \mathrm{~h}$, spacing of $1 \% \mathrm{~s}$, yaw angle of $0.3^{\circ}$ and tip radius of $6 \% \mathrm{~h}$.

(a)

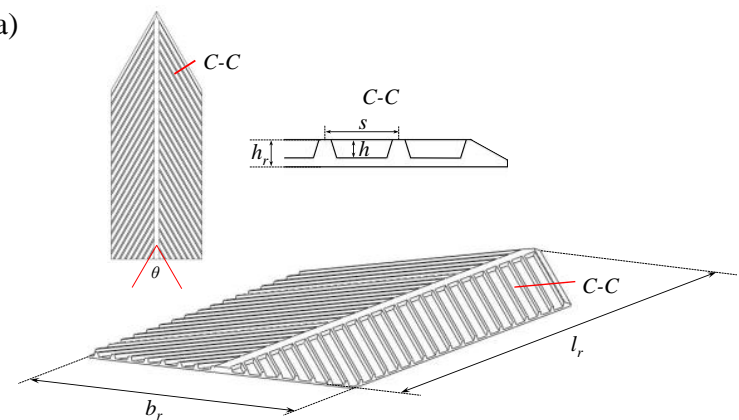

(b)

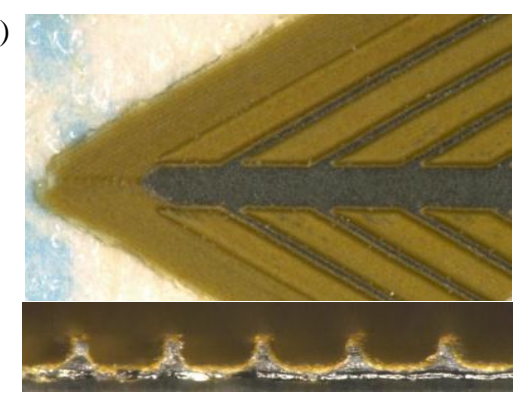

Figure 3 Design of Herringbone riblets. (a) Geometric parameters of herringbone riblets. (b) Microscopic view of the herringbone riblets manufactured using laser.

To investigate the effect of riblet height on the performance of the linear cascade, herringbone riblets with the same riblet spacing $(s=0.01 \mathrm{c})$ and three different riblet heights $(h=0.0013 \mathrm{c}, 0.0027 \mathrm{c}$ and $0.0046 \mathrm{c})$ were manufactured on foils with a thickness of $h_{r}=0.002 \mathrm{c}, 0.0033 \mathrm{c}$ and $0.0053 \mathrm{c}$, respectively. The riblet foils were applied on the blades with the same start position $\left(l_{L E}=0.5 \mathrm{c}\right)$. Furthermore, to examine the effects of riblet spacing, herringbone riblets with three different riblet spacing $(0.005 \mathrm{c}, 0.01 \mathrm{c}$ and $0.02 \mathrm{c})$ and the same height of $0.0027 \mathrm{c}$ were manufactured on foils with a height of $h_{r}=0.0033 \mathrm{c}$, starting at $l_{L E}=0.5 \mathrm{c}$. Finally, in order to understand the effect of riblet start position on the blades, an experiment was also carried out with the riblet foils fixed at $0.1 \mathrm{c}, 0.3 \mathrm{c}$ and $0.5 \mathrm{c}$ from the leading edge of the blades, respectively. In this last experiment, the riblet height of $0.0027 \mathrm{c}$ and riblet spacing of $0.01 \mathrm{c}$ were used. In all experiments, the length and width of the riblet foils as well as the gap between adjacent foils were kept the same. To ensure the mechanical integrity of riblet foils the riblets were not machined all the way through the entire thickness of the foils and a layer of foil material with a thickness $\left(h_{r}-h\right)$ of $0.0007 \mathrm{c}$ was left at the bottom of riblet valleys in all cases.

\subsection{Experimental and data processing methods}

To evaluate the pressure losses in the cascade, measurements with a five-hole probe were performed on a cross-stream plane located at $0.6 \mathrm{c}$ downstream of the exit plane of the cascade (see Figure 2a). The probe was brought from Limmat Scientific AG. It is an L-shape probe with the five pressure orifices being arranged in a cross pattern on its tip. The probe tip has a diameter of $0.9 \mathrm{~mm}$ which is believed to produce a negligible blockage to the flow. The coordinate system used in the present setup is shown in Figure 2a, with $\mathrm{x}$-, $\mathrm{y}$ - and $\mathrm{z}$-axis referring to the direction normal to the measurement plane, along the blade pitch and along the blade span, respectively. 
The five-hole probe was traversed along nine spanwise measurement lines with a spanwise spacing of 1/4. As shown in Figure $2 b$, the measurement area covered the central riblet foil and a half of the adjacent riblet foil located on each side. The solid lines are aligned with the diverging lines of the herringbone riblets whereas the dotted lines are aligned with the mid-point between two adjacent foils. At each spanwise position, the measurements were taken at twenty-three equally spaced points across a single blade passage behind the central blade. At each measurement point, the data were collected with a sampling frequency of $1 \mathrm{kHz}$ for 10 seconds using a data acquisition card with 16 bit resolution.

Before the experiments, the five-hole probe was calibrated over a range of velocities from $20 \mathrm{~m} / \mathrm{s}$ to $80 \mathrm{~m} / \mathrm{s}$ and for pitch and yaw angles up to $\pm 20^{\circ}$ in $5^{\circ}$ increments [22]. The calibration chart showed an excellent consistency over the velocity range tested. With the aid of this calibration chart, the total pressure, the three velocity components and flow angles at the measurement point were deduced by post-processing the data obtained with the probe.

With the local total pressure data, $P_{T, o u t}$, deduced from the measurement, the local total pressure loss coefficient can be calculated using the formula below:

$$
\gamma=\frac{P_{T, \text { in }}-P_{T, \text { out }}}{P_{T, \text { in }}-P_{S, \text { in }}}
$$

where $P_{T, i n}$ is the upstream total pressure measured and $P_{S, \text { in }}$ is the upstream static pressure. A typical contour plot of total pressure loss coefficient obtained from the experiments is presented in Figure 4a. The contour map reveals a distinct wake zone with high loss coefficient surrounded by a potential flow with low loss coefficient.

The pitch-wise distributions of loss coefficient along the nine measurement lines across the mid-span are shown in Figure 4b. The profiles appear to almost coincide with each other, confirming the good two-dimensionality of the flow. The thick (red) line is the averaged pitch-wise distribution of loss coefficient along all spanwise measurement stations, $\gamma_{s a} \cdot \gamma_{s a}$ reaches its maximum $\gamma_{\max }$ at $y_{\text {ymax }}$. The width of wake, $y_{w}$, can be defined as the pitch-wise distance over which $\gamma_{s a}$ is greater than $10 \%$ of $\gamma_{\max }$.

To facilitate a quantitative comparison between different cases, assuming incompressible flow a zoneaveraged mass-flow weighted loss coefficient behind one flow passage is introduced as follows:

$$
\gamma_{a}=\frac{\sum_{i=1}^{n} u_{i} \gamma_{i}}{\sum_{i=1}^{n} u_{i}}
$$

where $\gamma_{i}$ and $u_{i}$ are the local loss coefficient and streamwise velocity component at a measurement point respectively, and $n$ is the total number of measurement points on the measurement plane. The percentage of loss reduction in each case can then be calculated as,

$$
\xi=\frac{\gamma_{a}-\gamma_{a}^{\prime}}{\gamma_{a}} \times 100 \%
$$

where $\gamma_{a}$ is the zone-averaged loss coefficient in the baseline case, and $\gamma_{a}^{\prime}$ is the zone-averaged loss coefficient in the riblet case.

The flow turning angles on the measurement plane can also be extracted from the five-hole probe data. This angle indicates how well the blades are capable of guiding the flow in a predetermined flow path. In the experiments, the flow turning angle is defined as the angle between the inlet flow velocity vector and the local outlet velocity vector at a measurement point. As shown in Figure 4c, the pitchwise distribution of spanwise-averaged flow turning angle, $\varphi_{s a}$, firstly increases gradually towards a maximum, $\varphi_{\max }$, and it then decreases sharply to a minimum turning angle, $\varphi_{\min }$, before returning to the constant flow turning angle in the potential flow. For each given case, a zone-averaged mass-weighted turning angle $\left(\varphi_{a}\right)$ on the measurement plane behind one flow passage can be defined in a similar manner as for the pressure losses to enable a quantitative comparison among different cases, i.e. 


$$
\varphi_{a}=\frac{\sum_{i=1}^{n} u_{i} \varphi_{i}}{\sum_{i=1}^{n} u_{i}}
$$

The pressure transducers used for measuring the total pressure and static pressure at the cascade inlet and the pressure from the five-hole probe were estimated to have a measurement accuracy of $1 \%$. The calibration process of the five-hole probe brought about an uncertainty in the measurement of total pressure and flow angle range of $\pm 0.7 \%$ within $\left(-20^{\circ}, 20^{\circ}\right)$ and $\pm 0.4 \%$ within $\left(-10^{\circ}, 10^{\circ}\right)$ range. The uncertainty in the measurement the flow angle itself was $\pm 0.3^{\circ}$ within $\left(-20^{\circ}, 20^{\circ}\right)$ and $\pm 0.2^{\circ}$ within $(-$ $\left.10^{\circ}, 10^{\circ}\right)$. The resultant uncertainty in the measurement of total pressure and flow turning angle due to the uncertainty in both pressure transducers and the calibration process was estimated to be around $2 \%$ and $0.5^{\circ}$, respectively. Finally, the above measurement uncertainties would translate into a maximum uncertainty of $3 \%$ and $0.8^{\circ}$ in the zone-averaged loss coefficient and flow turning angle respectively, and a maximum uncertainty of $8 \%$ in the percentage of loss reduction.

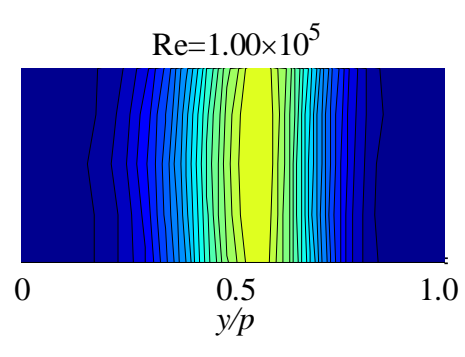

(a)

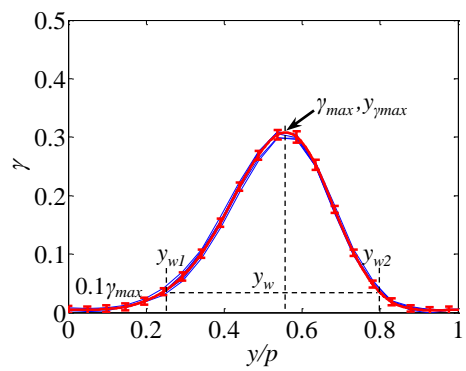

(b)

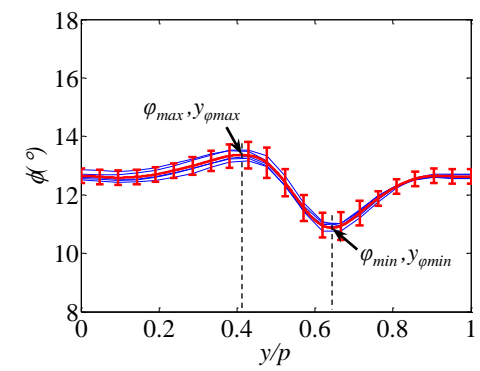

(c)

Figure 4 (a) A typical contour map of pressure loss coefficient obtained on the measurement plane; (b) Pitchwise variations of loss coefficient with error bars; (c) pitchwise variations of flow turning angle with error bars. The thin (blue) lines represent distributions obtained at different spanwise measurement locations. The thick (red) lines represent the spanwise-averaged distributions.

\section{Results and discussions}

The experiments were conducted at five different Reynolds numbers between $0.50 \times 10^{5}$ and $1.50 \times 10^{5}$ with the blades set at an incidence angle of $9^{\circ}$ (see Figure 5). The freestream Mach number was between 0.07 to 0.2 . The free-stream turbulence intensity was measured to be about $2 \%$, using a single-wire hot-wire probe placed before the inlet of the test section.

\subsection{The baseline cases}

Before the riblets were applied, the baseline cases without riblets (smooth blades) were established against which the effectiveness of herringbone riblets was evaluated. The surface flow visualization was first performed on the blade suction surface to reveal the locations of flow separation and reattachment in the baseline cases. The oil-flow visualization images in Figure 5a shows the development of surface flow pattern with an increasing Reynolds number. At $\operatorname{Re}=0.50 \times 10^{5}$, a nearly two-dimensional flow pattern across almost the entire span is observed with flow separation starting around $0.58 \mathrm{c}$ without the occurrence of flow reattachment. An increase of Re to $0.75 \times 10^{5}$ and then to $1.00 \times 10^{5}$ causes a gradual downstream shift of the separation position which is accompanied by corner vortices with an increasing strength. At $\mathrm{Re}=1.25 \times 10^{5}$, the separation line stays at almost the same position as at $\operatorname{Re}=1.00 \times 10^{5}$, and the separated flow reattaches before the trailing edge at $0.91 \mathrm{c}$, resulting in formation of a separation bubble. A further increase of Re to $1.50 \times 10^{5}$ does not seem to cause a noticeable change in the position of separation and reattachment line. The signals from a surface mounted hot-film fixed at $0.5 \mathrm{c}$ (not shown here) confirmed that the boundary layer flow was laminar before the location of flow separation over the range of Re tested. Therefore, an unattached laminar flow separation occurs at $\mathrm{Re}=0.50 \times 10^{5}$ and $0.75 \times 10^{5}$ and as $\mathrm{Re}$ increases a laminar flow separation bubble appears, possibly starting from $\mathrm{Re}=1.00 \times 10^{5}$. Hence, in the present experiments the 
development of surface flow pattern with an increasing Re from $0.50 \times 10^{5}$ to $1.50 \times 10^{5}$ is consistent with what one would expect to see in the low Reynolds number regime [23, 24].

Steady RANS simulations at the same working conditions were conducted with the SST k- $\omega$ turbulence model coupling with $\gamma-\mathrm{Re}_{\theta}$ transition model [25] using STAR-CCM+. The computational domain included one single passage, with the inlet located at $0.7 \mathrm{c}$ upstream of the blade leading edge and the outlet at $2 \mathrm{c}$ downstream of the blade trailing edge. Only half blade span was simulated as the cascade was symmetric with respect to the blade mid-span. The second-order upwind scheme was used for spatial discretization. A residual of $10^{-6}$ was set as the convergence criterion for all governing equations. A mesh sensitivity study was carried out on four cases with a total number of mesh cells of $1.15 \times 10^{6}, 1.75 \times 10^{6}, 2.65 \times 10^{6}$ and $3.97 \times 10^{6}$, respectively. Based on this study, the mesh with $2.65 \times 10^{6}$ mesh cells was chosen since a further increase in the number of mesh cells to $3.97 \times 10^{6}$ only produced a difference of $2 \%$ in the pressure loss coefficient.

In Figure 5b, the surface streamlines produced with the CFD results are shown. The computed skinfriction lines are in good agreement with the oil flow patterns in the location of the first flow separation region at the mid span for the range of Reynolds numbers tested (compare Figure 5a and $5 b)$. However, considerable differences in the surface flow patterns between the oil flow results and the simulations results exist within the separated flow region at $\operatorname{Re} \geq 1.00 \times 10^{5}$. Therefore, it can be included that the numerical model used here is capable of modelling the flow well before the flow separation occurs but not in modelling separated flow transition.

Figure 5c shows the locations of separation lines (SL) and reattachment lines (RL) at the blade midspan for all these cases. It can be seen that over the range of Reynolds numbers tested the flow separation occurs not before $0.58 \mathrm{c}$. Based on this information, the start positions of riblet foils $\left(l_{\mathrm{LE}}\right)$ were chosen to be not greater than $0.5 \mathrm{c}$ to ensure some levels of control on flow separation.

Figure 6a presents the contours of total pressure loss coefficient at the five different Reynolds numbers. All contours exhibit a wake zone associated with a relatively high loss coefficient (red and yellow) surrounded by a potential flow associated with a low loss coefficient (blue). At low $\mathrm{Re}=0.50 \times 10^{5}$ and $0.75 \times 10^{5}$, the loss is higher near the mid-span in the wake zone, resulting in a spindle-shaped contour map. From $\mathrm{Re}=1.00 \times 10^{5}$ onwards, the wake flow appears to be essentially two-dimensional across the blade span. The observed change in the wake characteristics could be related to a transition from fully laminar separation state to laminar separation bubble state (i.e., laminar separation followed by turbulent reattachment) on the blade suction surface.

Since the riblet foils have a finite thickness, when they are adhered onto the smooth surface of the blades they may perturb the near-wall flow thereby causing changes in the flow characteristics. In order to assess the effect of the foil thickness on the blade aerodynamic performance, experiments with blades fitted with smooth foils with a thickness of $0.0027 \mathrm{c}$ used in our tests were carried out. These foils had the same external shape and dimension as the riblet foils with herringbone riblets. The contours of loss coefficient for the smooth foil cases are shown in Figure 6b. It can be seen that at Re $=0.50 \times 10^{5}$ and $0.75 \times 10^{5}$, the smooth foils have improved the uniformity of the loss coefficient distribution across the span, indicating that the smooth foils with a finite thickness have exerted some effects on the near-wall flow. The negligibly reduced $\gamma_{a}$ in Figure 7 also shows that the smooth foils have only made the mid-span flow separation uniform rather than reducing it. As can also be seen in Figure 6 , at $\operatorname{Re}=1.00 \times 10^{5}$ and $1.25 \times 10^{5}$, there is little difference between the contours of loss coefficient for the smooth blades and blades with smooth foils. These negligible differences can also be observed in the rest of the line plots in Figure 7. Therefore, in the subsequent sections, the results from the ribleted cases will be compared directly with their corresponding baseline cases with smooth blades. 
(a)

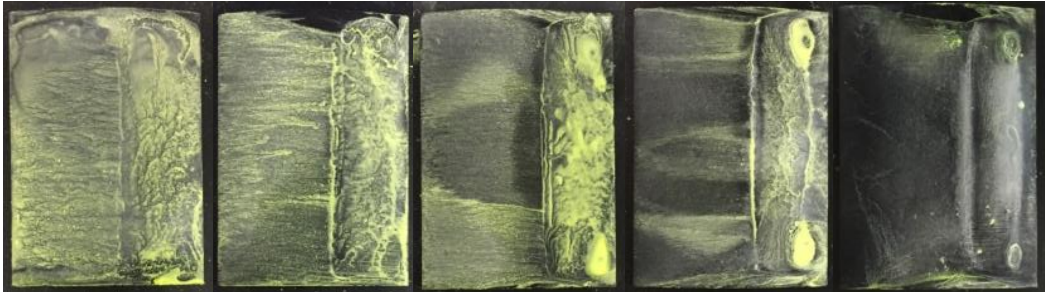

$\operatorname{Re}=0.50 \times 10^{5} \quad \operatorname{Re}=0.75 \times 10^{5} \quad \operatorname{Re}=1.00 \times 10^{5} \quad \operatorname{Re}=1.25 \times 10^{5} \quad \operatorname{Re}=1.50 \times 10^{5}$

(b)
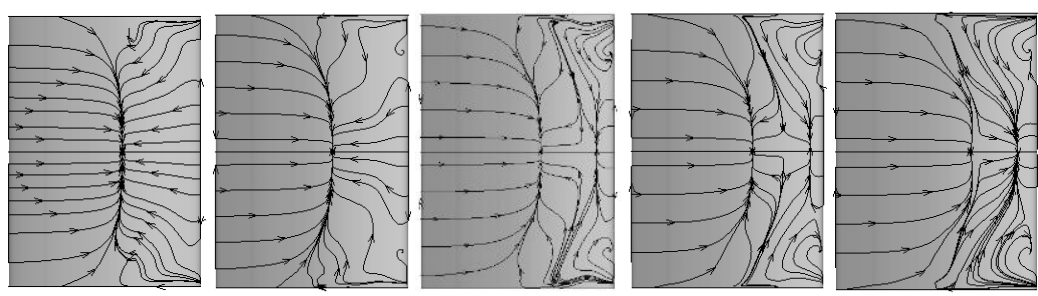

(c)

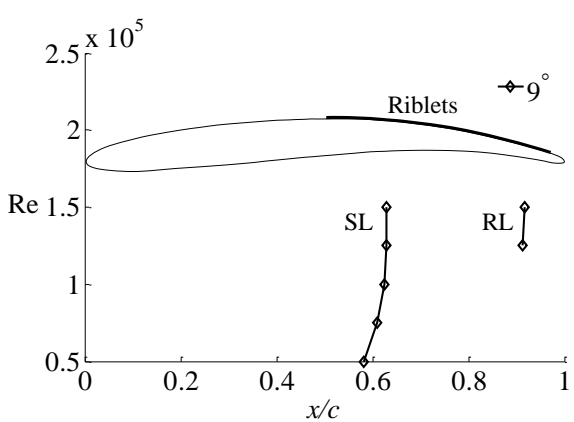

Figure 5 Oil flow visualization results on suction surface at five different Re at incidence of $9^{\circ}$. (a) oil flow visualization results; (b) skin friction lines from numerical simulations; (c) locations of flow separation and reattachment at the mid-span from oil flow visualization.

a)

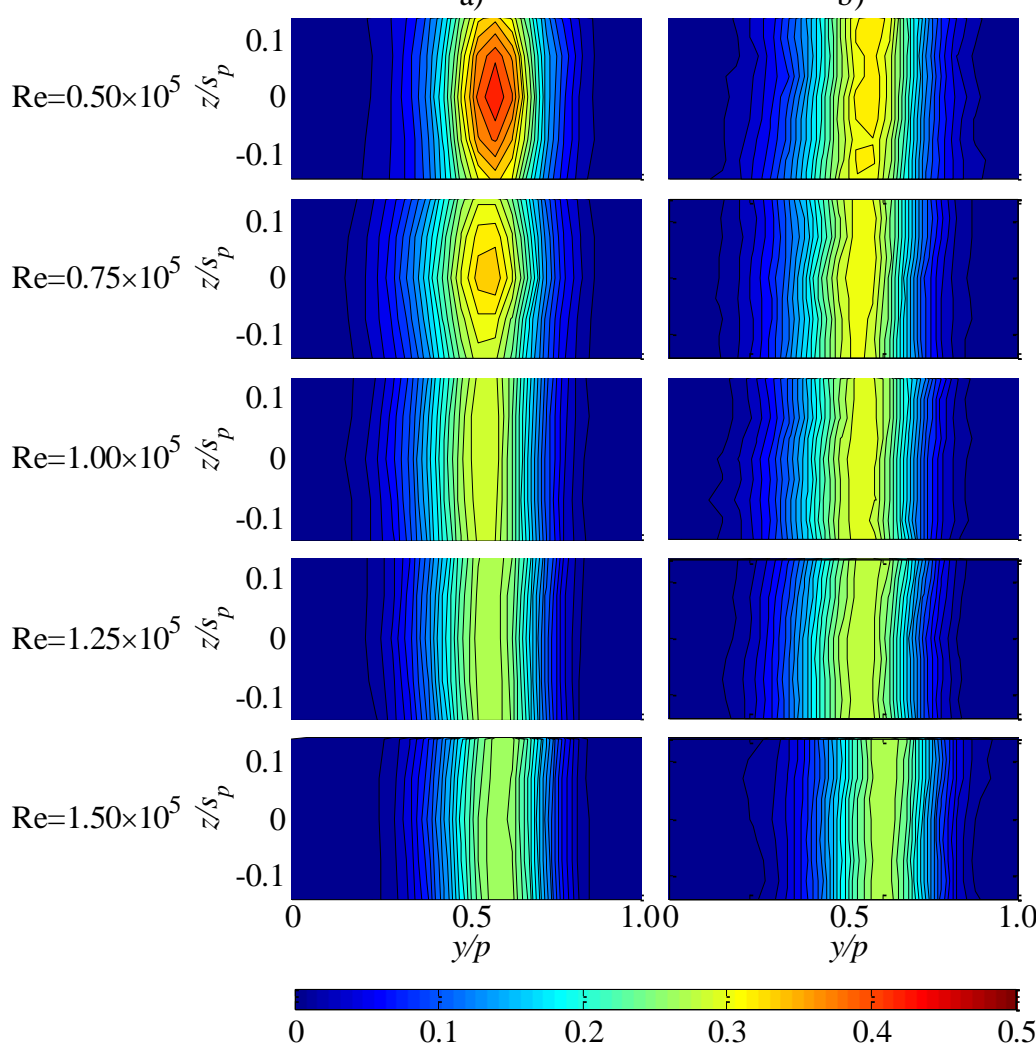

(i)

(ii)

Figure 6 Loss coefficient contours in the cases with a) smooth blades; b) smooth foils with a foil thickness of $0.0027 \mathrm{c}$ at (i) $\operatorname{Re}=0.5 \times 10^{5}$; (ii) $\operatorname{Re}=0.75 \times 10^{5}$; (iii) $\operatorname{Re}=1.00 \times 10^{5}$; (v) $\operatorname{Re}=1.25 \times 10^{5}$; (v) $\operatorname{Re}=1.50 \times 10^{5}$. 


\subsection{Effects of herringbone riblets with different riblet heights}

In this section, the effects of herringbone riblet height were investigated. The riblets have the same spacing of $0.01 \mathrm{c}$ and three different heights of $0.0013 \mathrm{c}, 0.0027 \mathrm{c}$ and $0.0046 \mathrm{c}$ were tested.

Figure 8(b)-(d) show that the loss coefficient contours for the cases with the three riblet heights at five Reynolds numbers. Also compared are the baseline smooth airfoil cases. It is apparent that a dramatic effect in terms of changes in the wake structure occurs at certain Reynolds number. It can be regarded as critical Reynolds number ( $\mathrm{Re}_{\text {crit }}$ ) for a given riblet height. The critical Reynolds number at which the change in wake structure is observed reduces as the height of the herringbone riblets increases. Below the critical Reynolds number, the herringbone riblets only improve the uniformity of loss coefficient distribution in the wake zone. More specifically, the observed change in the wake structure is manifested by a narrowed width, a shift in location towards the suction surface of the blade and the appearance of a serrated structure. A narrow and smaller wake together with a shift in wake location is a clear sign of a reduced extent of flow separation on the blade suction surface. It is noted that the regions of lower and higher pressure loss in the serrated structure switch positions at $\operatorname{Re}=1.50 \times 10^{5}$ in the case with the largest riblet height. The reason for this is still unclear. But it could be caused by an increased local skin friction drag due to the use of a large riblet height.

The serrated structure observed in the contours of pressure loss coefficient is believed to be caused by the modification of the near-wall flow by the herringbone riblets. It is known that convergentdivergent riblets generate a weak time-averaged secondary flow motion (or roll mode) in the crossstream plane of a boundary layer [17-19]. Such a secondary flow motion will enhance mixing, hence enabling the boundary layer to resist an adverse pressure gradient. Over the diverging line, the fluid is forced to move away from the diverging line, resulting in a downwash flow which leads to a higher local streamwise velocity and a thinner boundary layer in this region. The opposite occurs over the converging line. As such, a slightly narrower wake zone and lower loss coefficient will appear behind the diverging region of herringbone riblet strips whereas a slightly wider wake zone and higher loss coefficient will appear behind the converging region (see Figure 9) resulting in the serrated structure observed in Figure 8.

It is known that randomly distributed surface roughness and even patterned surface roughness, such as longitudinal riblets, could act like agent of turbulence transition leading to reduction of laminar flow separation. However, the flow separation control mechanism of herringbone riblets is different and yet appears to be effective. The role of secondary flow in suppressing flow separation is evident by the fact that the control effect observed in the present experiment is always accompanied by the appearance of a serrated wake structure which is clearly produced by the specific surface patterns of herringbone riblets.

To enable a quantitative comparison among different cases, the zone-averaged loss coefficient $\left(\gamma_{a}\right)$, the spanwise-averaged wake width $\left(y_{w}\right)$ and maximum loss coefficient $\left(\gamma_{\max }\right)$ for all cases are presented in Figure 10. It is clear from Figure 10a that for a given riblet height, herringbone riblets exert little effect on $\gamma_{a}$ before the critical Reynolds number and a step change in $\gamma_{a}$ occurs when the critical Reynolds number is exceeded. This Reynolds number at which such a step change in $\gamma_{a}$ occurs decreases as the riblet height increases. However, the maximum reduction in $\gamma_{a}$ achievable for a larger riblet height decreases. Such a result is not unexpected. This is because, on one hand taller herringbone riblets produce a stronger secondary flow motion hence a stronger flow control effect, however they are deemed to cause a higher parasitic drag of their own hence compromising the amount of pressure loss reduction. In addition, as Re increases the boundary layer developing over the blade suction surface becomes thinner, hence the parasitic drag produced by riblets of a given height will also increase. As shown in Figure 10b, in comparison to the corresponding baseline case the riblets with the three different heights produce a maximum reduction in $\gamma_{a}$ of $39.5 \%, 36.4 \%$ and $31.7 \%$ respectively over the range of Reynolds numbers tested. 
(a)

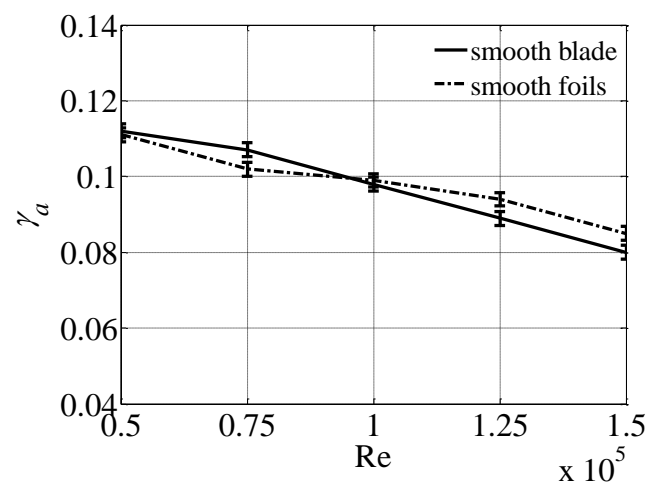

(c)

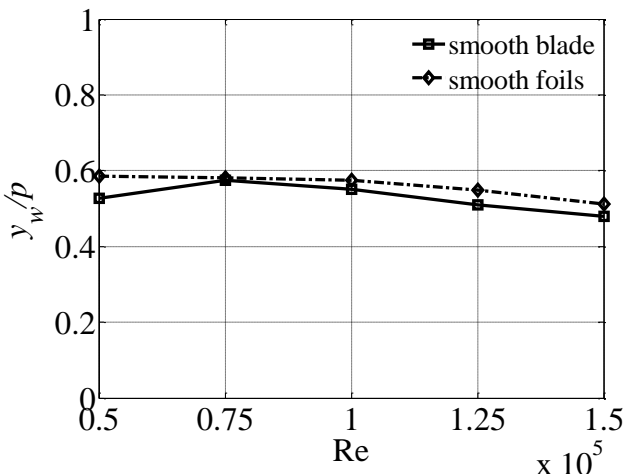

(b)

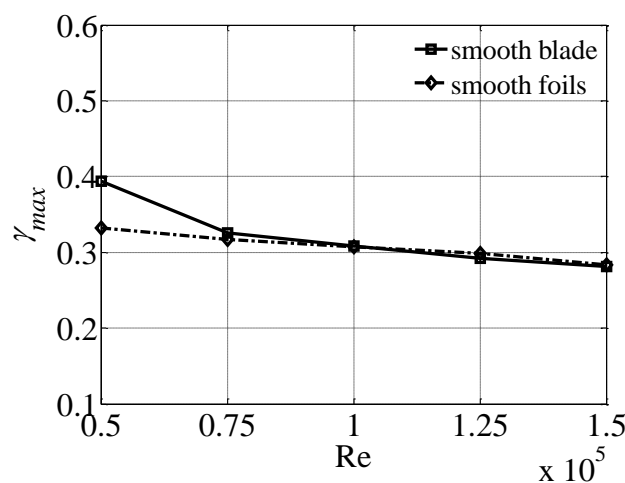

(d)

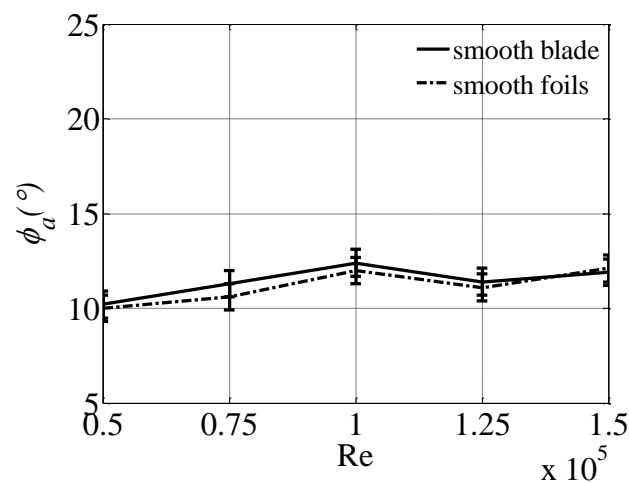

Figure 7 Comparison of (a) zone-averaged loss coefficient; (b) maximum spanwise-averaged loss coefficient; (c) spanwise-averaged width of wake zone; (d) zone-averaged flow turning angle.

a)
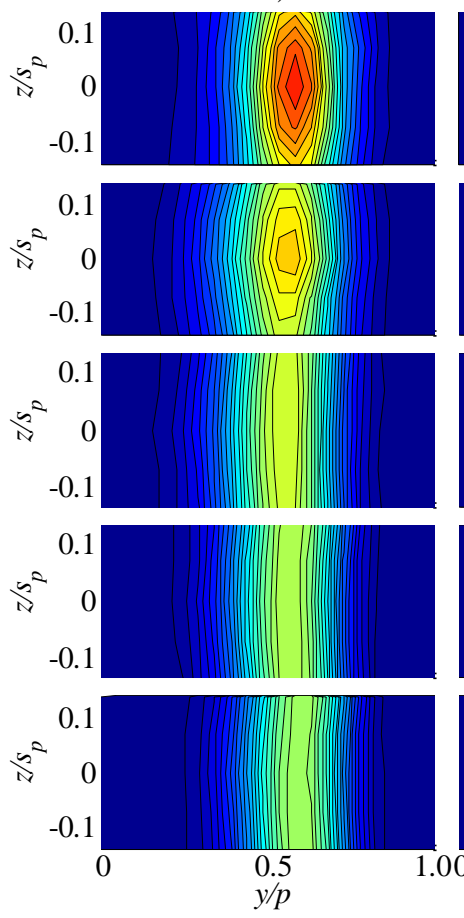

b)
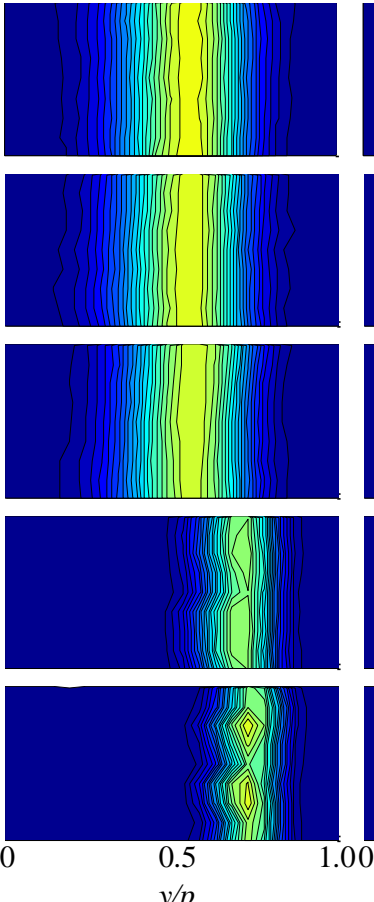

c)
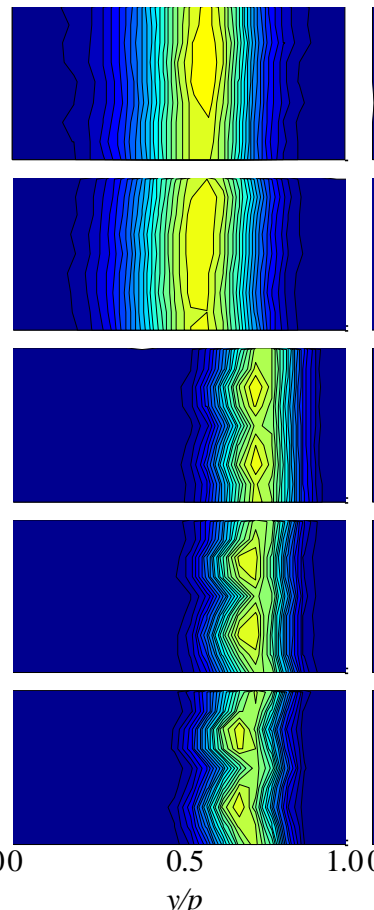

d)

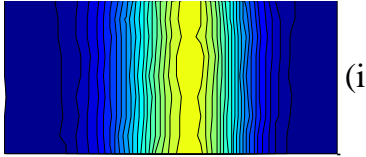

(i)
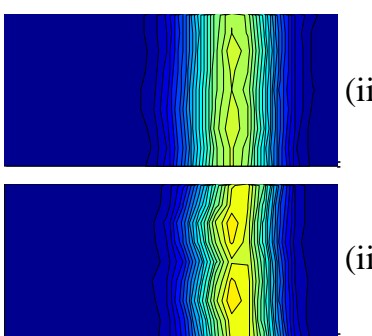

(iii)

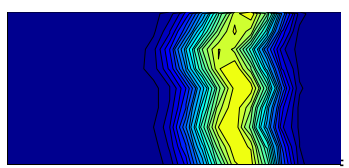

(iv)

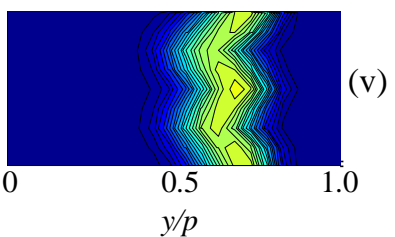

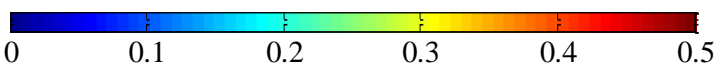

Figure 8 Effect of riblet height on contours of loss coefficient at different Reynolds numbers. (a) the baseline cases; with the same riblet spacing of $0.01 c$ and riblet height of (b) $0.0013 c$; (c) $0.0027 \mathrm{c},(\mathrm{d}) \mathrm{0.0046c}$ at $(\mathrm{i}) \mathrm{Re}=0.50 \times 10^{5}$; (ii) $\operatorname{Re}=0.75 \times 10^{5}$; (iii) $\operatorname{Re}=1.00 \times 10^{5}$; (iv) $\operatorname{Re}=1.25 \times 10^{5}$ and (v) $\operatorname{Re}=1.50 \times 10^{5}$. 


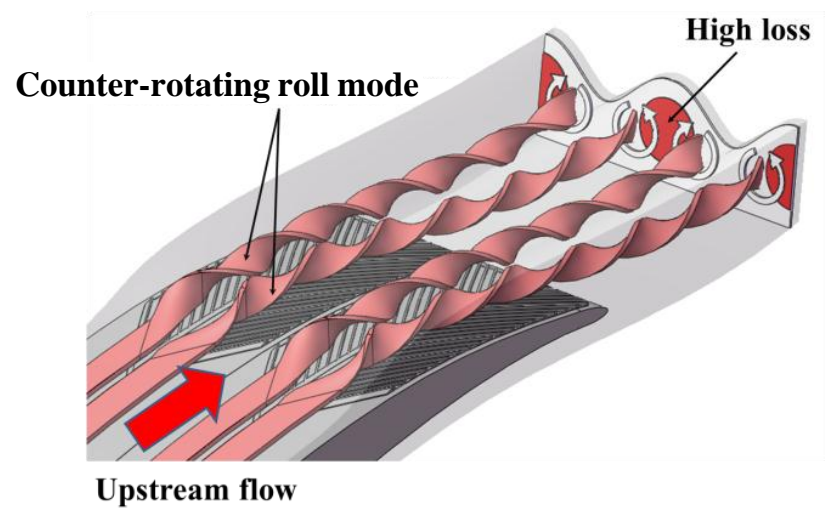

Figure 9 Hypothesized counter-rotating roll mode produced by herringbone riblets on the blade

Examining Figure 10a, 10c and 10d together, it can be concluded that herringbone riblets have very little effect on the maximum spanwise-averaged loss coefficient. The reduction of overall loss coefficient is thus the result of a reduction of the wake width, which is mostly likely to be caused by suppression of flow separation over the suction surface. Figure 10e compares the amount of increase in the zone-averaged flow angle $\left(\varphi_{a}\right)$ in the flow passage among different cases. The improvement in $\varphi_{a}$ follows a similar trend as the zone-averaged loss coefficient, i.e. taller riblets bring about the onset of an increase in the flow turning angle at a lower Re at the expense of a reduced $\Delta \varphi_{a}$ (see Figure 10f). The maximum $\Delta \varphi_{a}$ is $4.1^{\circ}$, achieved by riblets with a height of $0.0027 \mathrm{c}$ at a Reynolds number of $1.00 \times 10^{5}$.

(a)

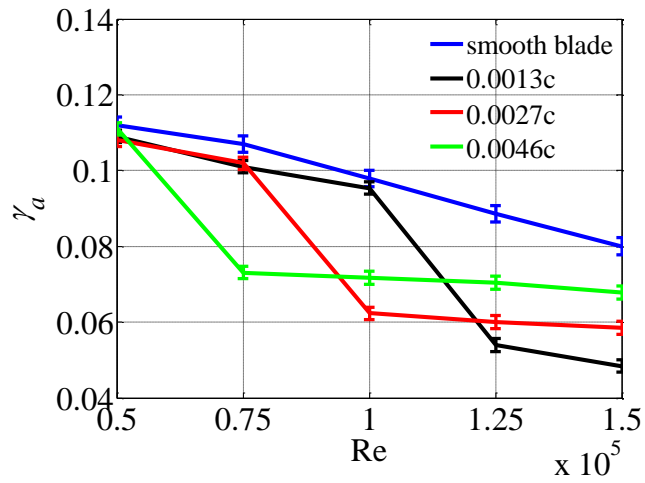

(c)

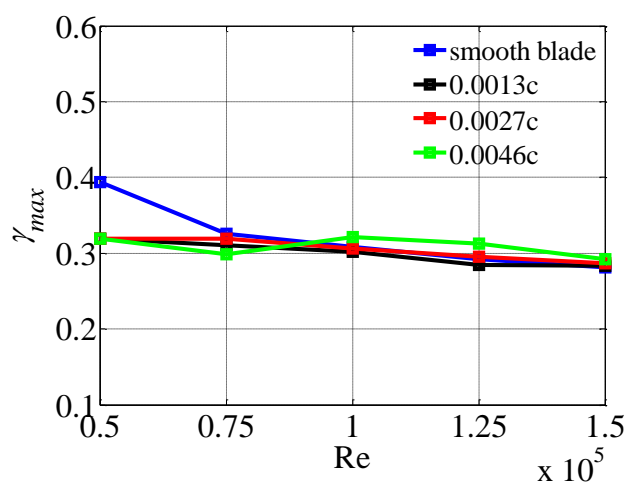

(b)

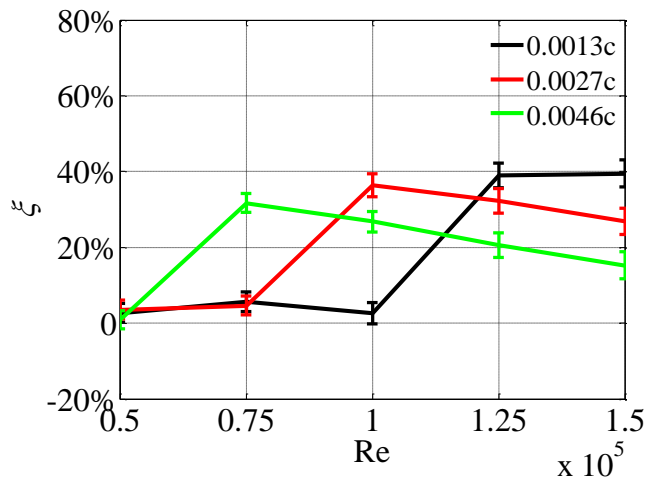

(d)

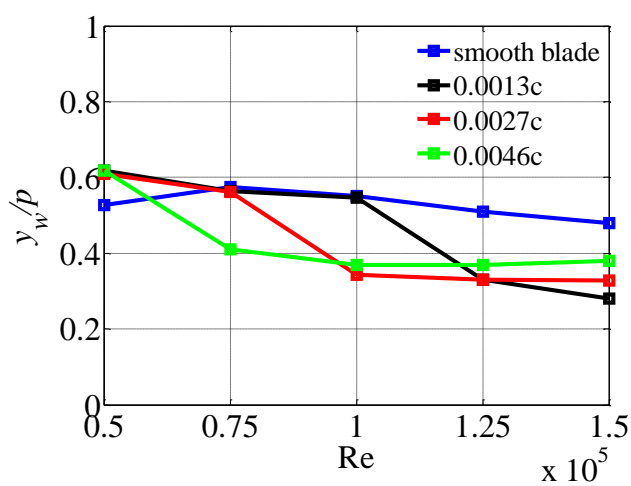


(e)

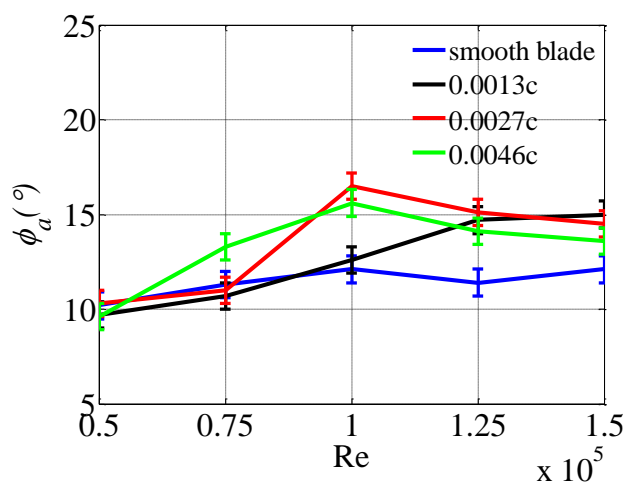

(f)

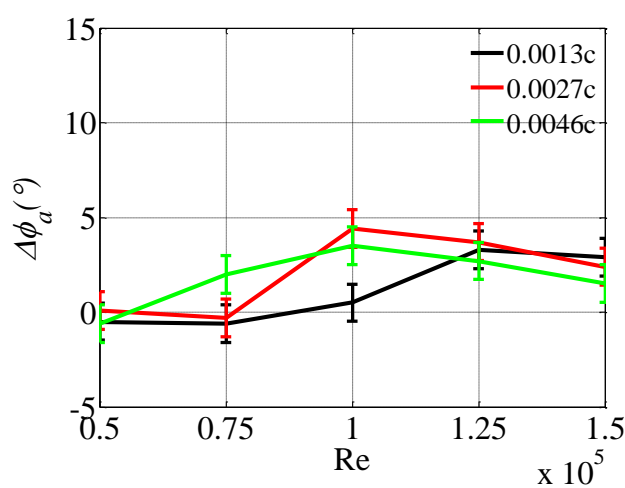

Figure 10 Effects of the herringbone riblet heights at different Reynolds numbers. (a) zone-averaged loss coefficient, (b) zone-averaged loss reduction percentage, (c) maximum loss coefficient, (d) width of wake affected zone. (e) zoneaveraged flow turning angle, and (f) increase in zone-averaged flow turning angle.

\subsection{Effects of herringbone riblets with different riblet spacing}

Next to be examined is the effect of riblet spacing on pressure losses and flow turning angles. The contours of loss coefficient for the test cases with the same riblet height of $0.0027 \mathrm{c}$ and three riblet spacing of $0.005 \mathrm{c}, 0.01 \mathrm{c}$ and $0.02 \mathrm{c}$ at the five different Reynolds numbers are presented in Figure 11.

As can be seen in Figure 11, with riblet spacing of $0.005 \mathrm{c}$, the tangential shift of the wake with the serrated structure first appear at $\mathrm{Re}=1.25 \times 10^{5}$. An increase in the riblet spacing to $0.01 \mathrm{c}$ seems to shift the onset of such an effect to a lower Reynolds number of $\mathrm{Re}=1.00 \times 10^{5}$. With a riblet spacing of $0.02 \mathrm{c}$, the serrated wake structure appears to be forming but not yet fully established at $\mathrm{Re}=0.75 \times 10^{5}$. As such, both the width and location of the wake are only affected slightly.

From Figure 12a, similar to the results in the cases with different riblet heights, the herringbone riblets are only capable of reducing $\gamma_{a}$ when the critical Re is exceeded. As the riblet spacing increases from $0.005 \mathrm{c}$ to $0.01 \mathrm{c}$, there is a decrease in the critical Reynolds number. As the riblet spacing increases further to $0.02 \mathrm{c}$, the critical Reynolds number decreases to a value between $\mathrm{Re}=0.75 \times 10^{5}$ and $1.00 \times 10^{5}$. Figure $12 \mathrm{c}$ shows that compared to the corresponding baselines cases the maximum loss reduction decreases slightly as the riblet spacing increases. Examining Figure 12a, 12c and 12d together, it can again be concluded that the herringbone riblets have little effect on the maximum loss coefficient and the resultant reduction of overall loss coefficient is thought to be caused by the narrowed wake region via a suppression of flow separation over the blade suction surface. Figure 12e and 12f show the zoneaveraged flow turning angles $\left(\varphi_{a}\right)$ in different cases and the increase in flow turning angle from the baseline cases. It is obvious that $\Delta \varphi_{a}$ experiences a similar trend with an increasing Reynolds number as that of the loss reduction shown in Figure 12b.

The diminished improvement in loss coefficient observed with increase in riblet spacing in Figure 12b could be caused by an increase in flow resistance over the riblets in the streamwise direction. According to Perry et al. [26], surface roughness in the form of spanwise grooves can be classified as either $d$-type roughness or k-roughness depending on the aspect ratio, $h / s$, of the grooves, see Figure 12. The $d$-type roughness is referred to narrow spanwise grooves $(\mathrm{s} \sim 1 h)$ over which stable recirculation vortices are formed within the grooves such that the outer flow goes over the roughness smoothly such that the presence of riblets is not felt by the flow. The $k$-type roughness is referred to wider grooves $(s>3 \sim 4 h)$ within which the recirculation bubble reattaches ahead of the next riblet hence exposing it to the outer flow and resulting in a higher parasitic drag. In the present experiments, with an increasing riblet spacing from $\mathrm{s} / \mathrm{h}=1.875$ to 7.5 the herringbone riblets switch from $d$-type to $k$-type roughness hence leading to a slightly increased pressure loss. As a compromise between creating a strong secondary flow motion and minimising the parasitic drag, it is likely that the riblets with the highest $s / h$ (around 3 4), which ensures a $d$-type roughness, are most desirable. 


\subsection{Effects of herringbone riblets with different start positions}

The effect of the herringbone riblets starting at three different chordwise locations, i.e. $l_{\mathrm{LE}}=0.1 \mathrm{c}, 0.3 \mathrm{c}$ and $0.5 \mathrm{c}$ from the leading edge of the blades, were investigated at different Re. The dimension of the riblet foils and the geometry of the microgrooves were kept the same.

The contours of loss coefficient for these cases are shown in Figure 13. It can be seen that with $l_{\mathrm{LE}}=$ $0.5 \mathrm{c}$ the critical Reynolds number at which the significant change in the wake structure occurs is at $\mathrm{Re}=1.00 \times 10^{5}$. When the start position of the riblet foils shifts upstream to $l_{\mathrm{LE}}=0.3 \mathrm{c}$, the critical Reynolds number is reduced to $\operatorname{Re}=0.75 \times 10^{5}$. However, a further upstream shift of riblets to $l_{\mathrm{LE}}=0.1 \mathrm{c}$ produces a very similar wake structure, except at the lowest Reynolds number of $\operatorname{Re}=0.50 \times 10^{5}$ at which a slight right shift in the wake structure accompanied by a slight reduction in the width of the wake is observed. This may be because the riblets have been moved into a much thinner boundary layer near the blade leading edge such that they have modified the local flow due to their finite thickness. Furthermore, with a closer examination of the serrated wake structures at the same Re, it can be noticed that the serrated structure appears slightly larger and stronger as the start position of the riblet foils moves upstream.

a)
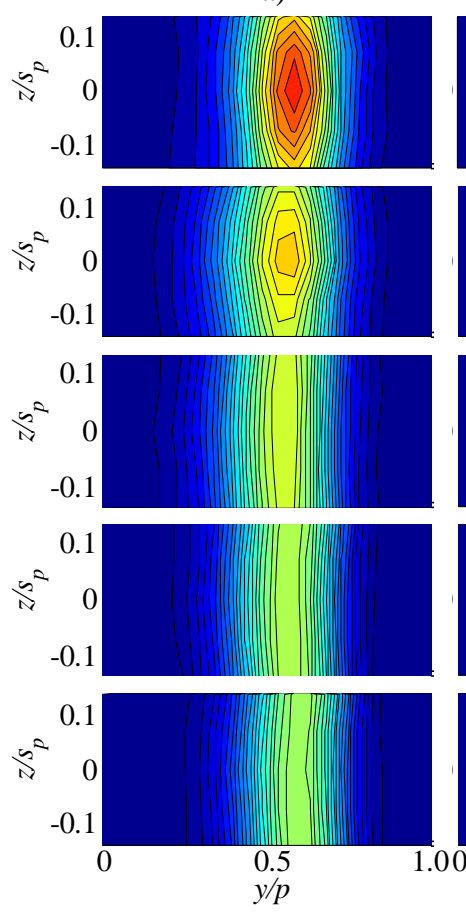

b)
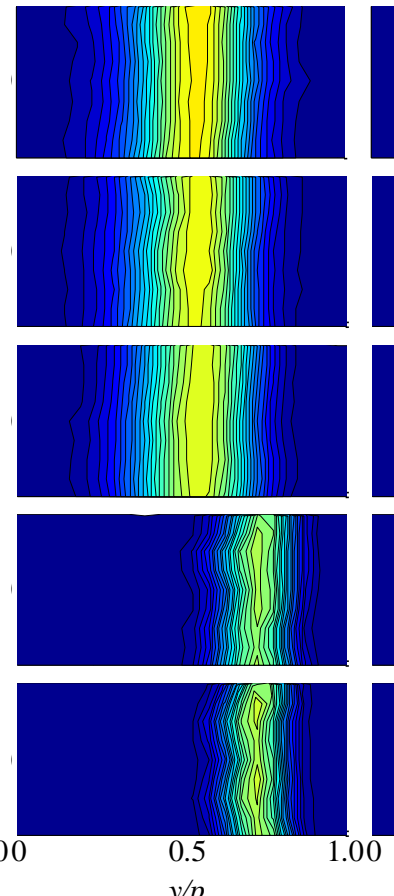

the c)
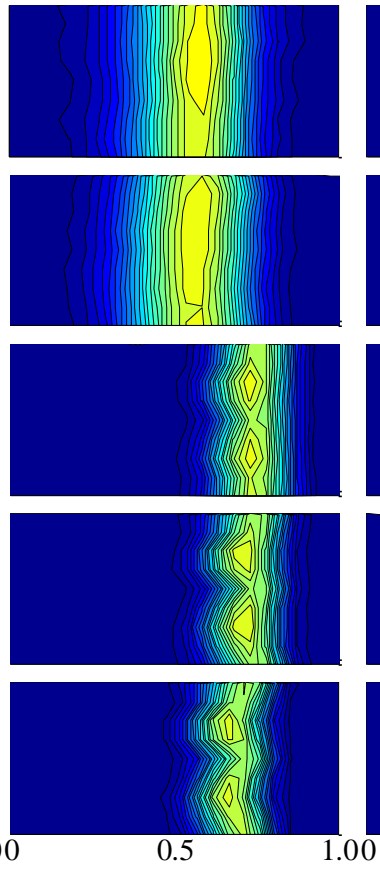

$y / p$ d)
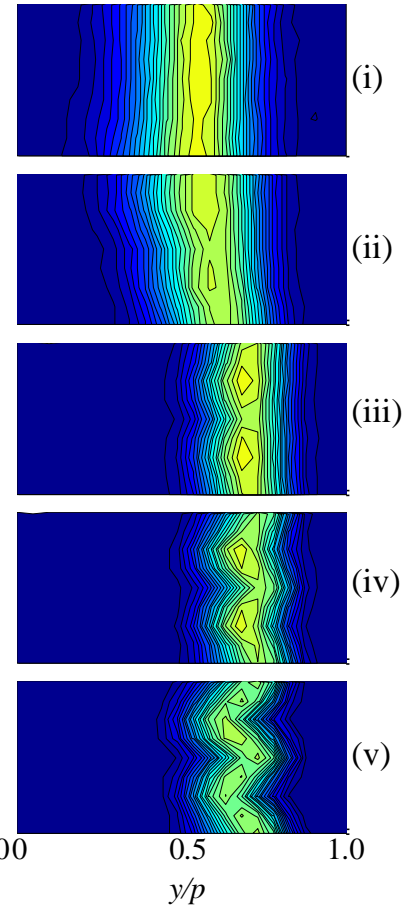

Figure 11 Effects of riblet spacing on contours of loss coefficient at different Reynolds numbers. (a) the baseline cases; with the same riblet height of $0.0027 \mathrm{c}$ and riblet spacing of (b) $0.005 \mathrm{c}$; (c) $0.010 \mathrm{c},(\mathrm{d})$. $0.020 \mathrm{c}$ at (i) $\operatorname{Re}=0.50 \times 10^{5}$; (ii) $\operatorname{Re}=0.75 \times 10^{5}$; (iii) $\operatorname{Re}=1.00 \times 10^{5}$; (iv) $\operatorname{Re}=1.25 \times 10^{5}$ and (v) $\operatorname{Re}=1.50 \times 10^{5}$ 
a)

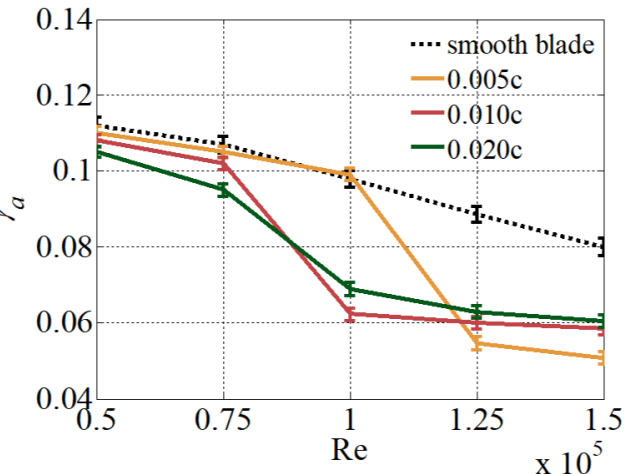

c)

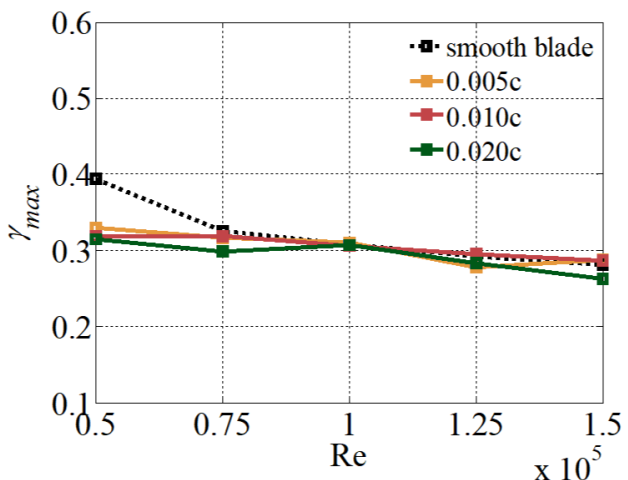

e)

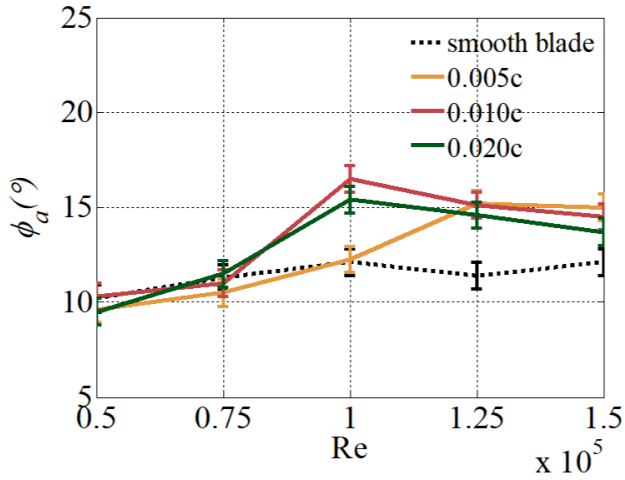

b)

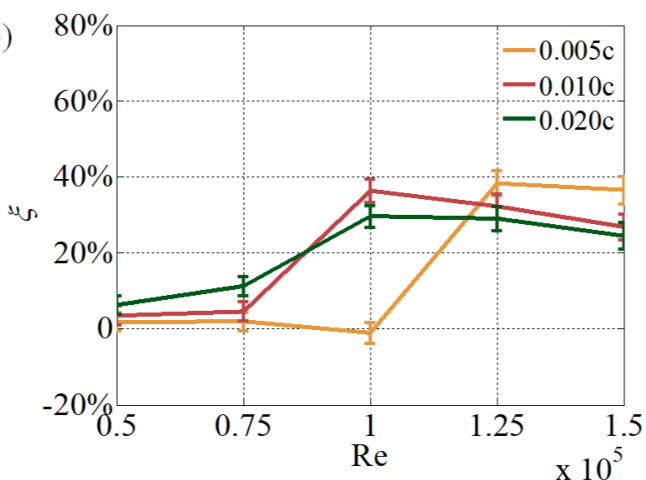

d)

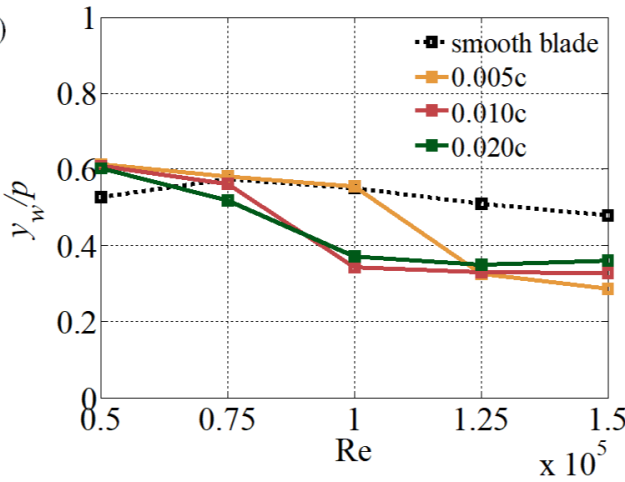

f)

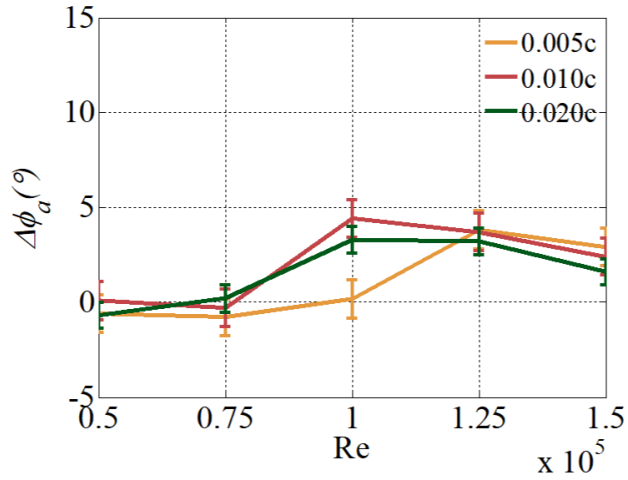

Figure 12 Effects of herringbone riblets on loss coefficient at five Re in the case with the same riblet height of $0.0027 \mathrm{c}$ and different riblet spacing of $0.005 \mathrm{c}, 0.01 \mathrm{c}$ and $0.02 \mathrm{c}$. (a) zone-average loss coefficient; (b) loss reduction percentage; (c) maximum loss coefficient; (d) width of wake zone; (e) zone-averaged flow turning angle, and (f) increase in zone-averaged flow turning angle.

(a)

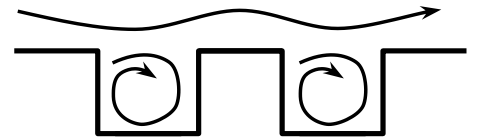

(b)

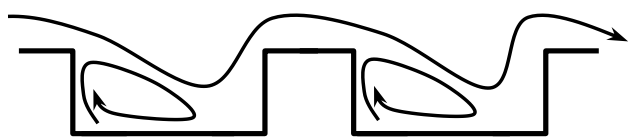

Figure 12 Flow patterns over (a) $d$-type roughness, and (b) $k$-type roughness. 
a)
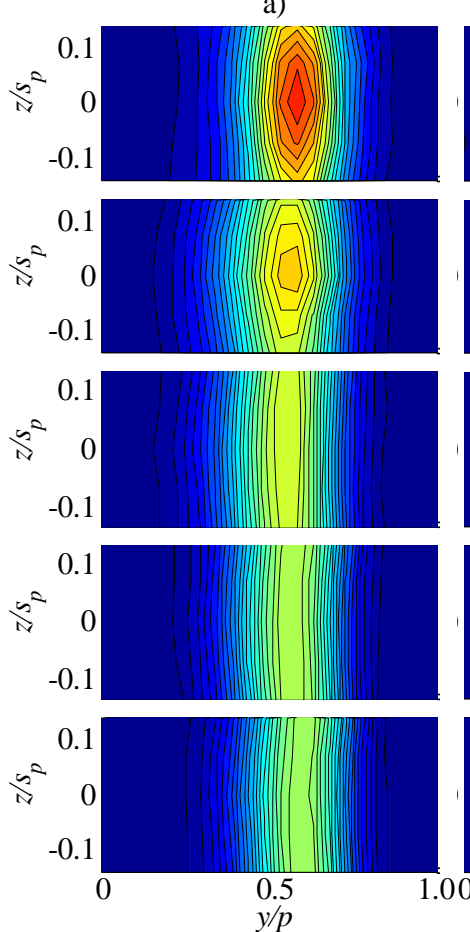

b)
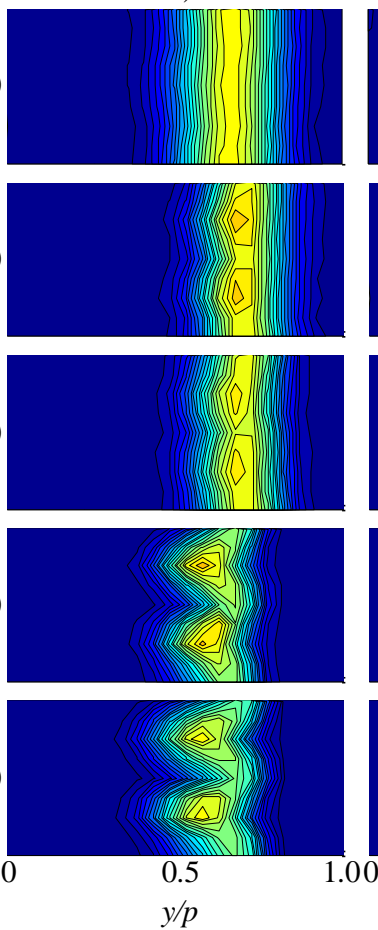

c)
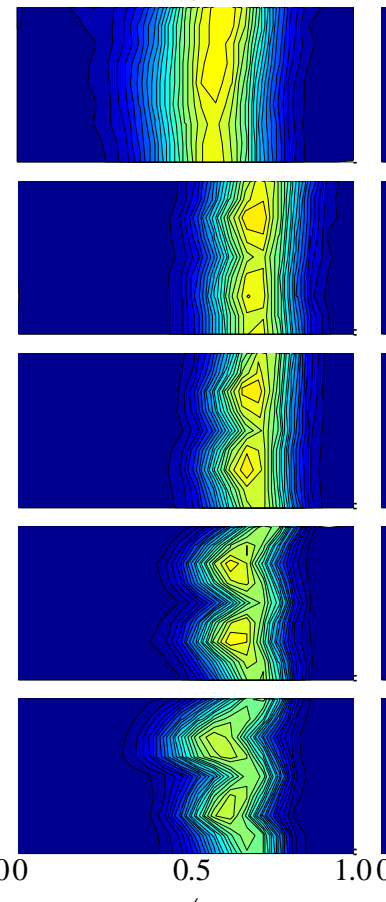

$y / p$ d)
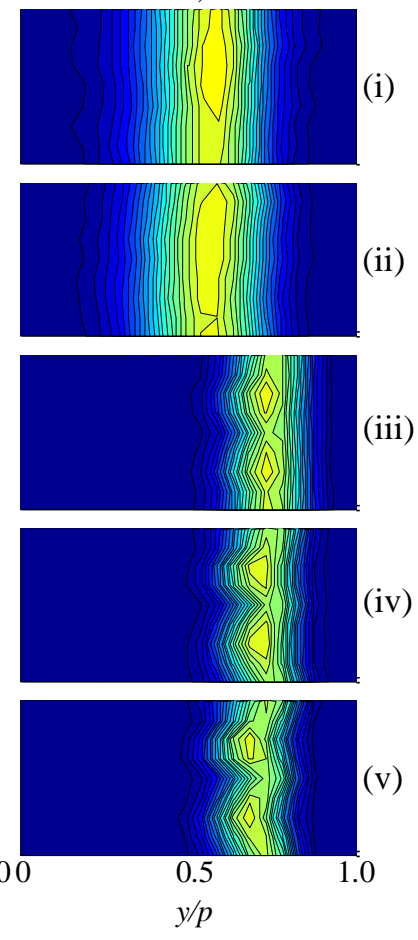

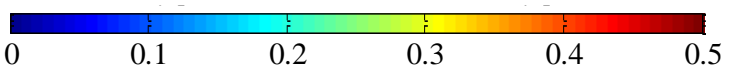

Figure 13 Effects of herringbone riblets with different start positions on the blades a) baseline cases, Reiblets starting from b) $0.1 c$, c) $0.3 c$ and d) $0.5 c$. at (i) $\operatorname{Re}=0.50 \times 10^{5}$; (ii) $\operatorname{Re}=0.75 \times 10^{5}$; (iii) $\operatorname{Re}=1.00 \times 10^{5}$; (iv) $\operatorname{Re}=1.25 \times 10^{5}$ and (v) $R e=1.50 \times 10^{5}$. Riblet height $h=0.0027 c$ and riblet spacing $s=0.01 c$.

From Figure 14, it can be observed that the riblets at $l_{\mathrm{LE}}=0.1 \mathrm{c}$ and $0.3 \mathrm{c}$ causes a reduction in the zoneaveraged pressure loss coefficient $\left(\gamma_{a}\right)$ and produce an increase in flow turning angle $\left(\varphi_{a}\right)$ compared to the corresponding baseline cases across the range of Reynolds numbers tested. However, there is a little difference in $\gamma_{a}$ and $\varphi_{a}$ between these two cases except at the lowest Reynolds number. Moving the riblets downstream to $0.5 \mathrm{c}$ leads to a step improvement in $\gamma_{a}$ and $\varphi_{a}$ when Re reaches the critical Reynolds number of $1.00 \times 10^{5}$. Furthermore, the improvement in loss reduction and flow turning is more compared to when the riblets were located upstream. Again, the reduction in $\gamma_{a}$ can be attributed to the narrowed wake caused by the riblets rather than a reduction in the maximum loss coefficient (compare Figure 14a, 15c and 15d).

The start position of the herringbone riblets is expected to affect the strength of the secondary flow produced by the riblets in two different ways. On one hand, an upstream shift of the riblets results in them being located underneath a thinner boundary layer. As such, the riblets of a given size are capable of producing stronger spanwise flow (hence, stronger secondary flow) to deliver the flow control effect. On the other hand, the secondary flow motion will be exposed to an adverse pressure gradient in the attached flow for a longer distance before they interact with a separated flow downstream causing them to appear more diffused and larger. Both factors can result in larger serrated wake structures observed with the riblets fixed at $l_{\mathrm{LE}}=0.1 \mathrm{c}$ and $0.3 \mathrm{c}$. 
(a)

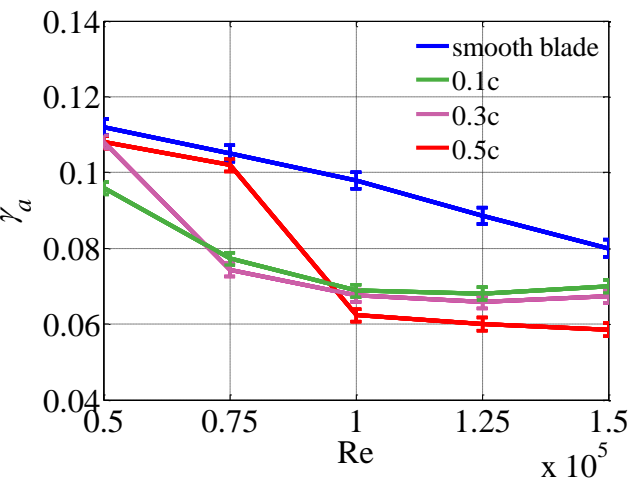

(c)

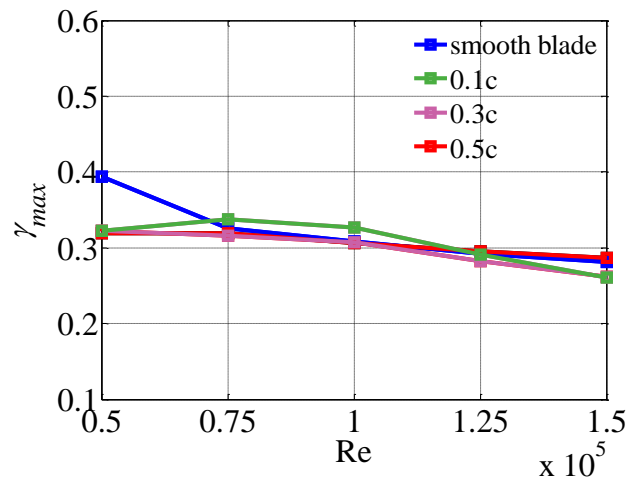

(e)

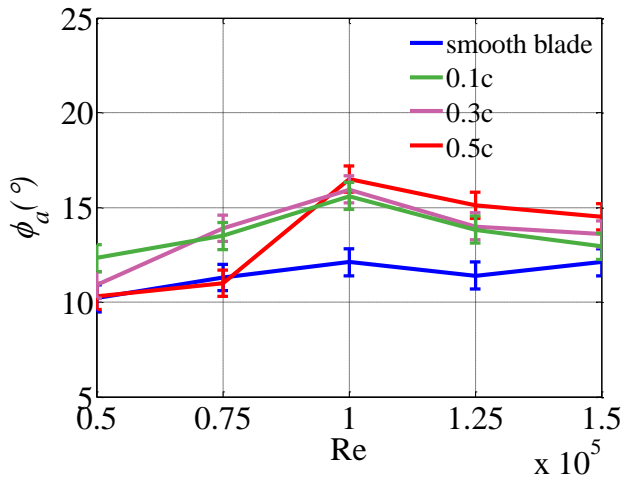

(b)

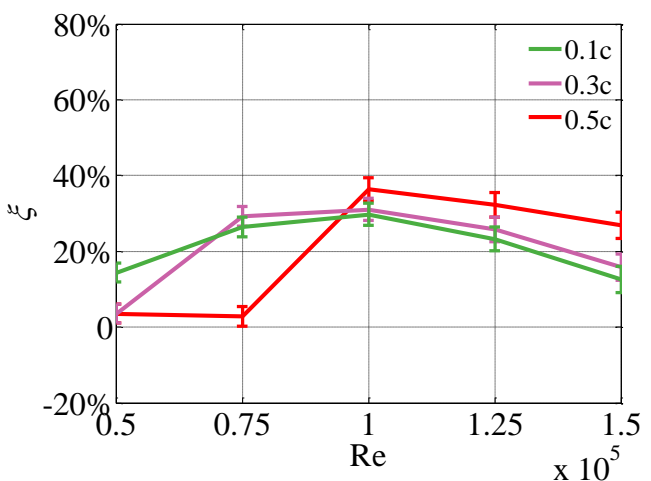

(d)

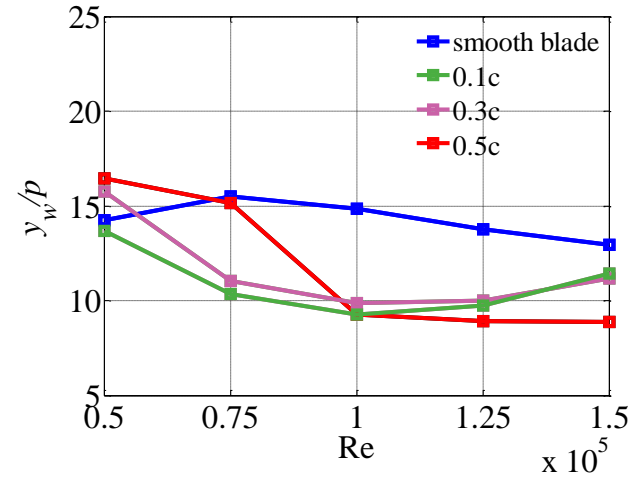

(f)

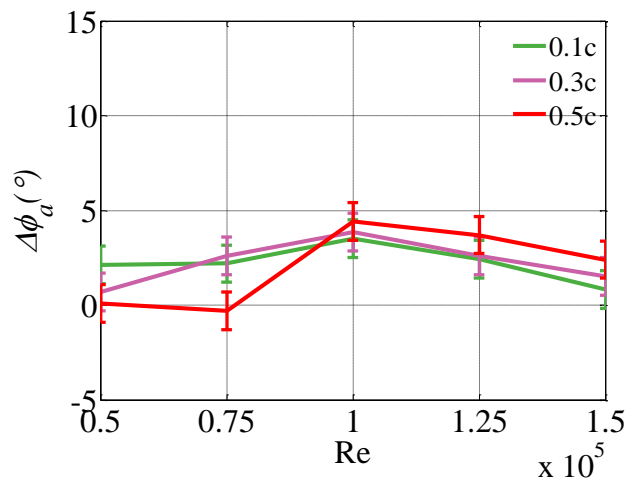

Figure 14 Effects of herringbone riblets with different streamwise start positions on the blade at five Re. (a) zoneaverage loss coefficient; (b) loss reduction percentage; (c) maximum loss coefficient; (d) width of wake zone; (e) zoneaveraged flow turning angle, and (f) increase in zone-averaged flow turning angle.

\subsection{Semi-empirical correlations between dimensionless riblet foil height and Reynolds number}

So far, the experimental results show that the effects of herringbone riblets on the performance of a linear cascade are affected by the choice of riblet height, riblet spacing and the start location of riblet foils. It is clearly seen that for a given riblet geometry and start location significant control effects only take place when certain critical Reynolds numbers are exceeded. For practical applications, it would be useful to know how the riblet geometry and start location should be selected to guarantee that a desired control effect is obtained for a given flow condition.

In this study, an attempt is made to establish a semi-empirical relationship between $h / \delta^{*}$ and the critical Re using the present experimental data and the results are presented in Figure 15a. $\delta^{*}$ is the local boundary layer displacement thickness at the leading edge of the riblet foils in the corresponding baseline case. Due to the difficulty in measuring the velocity profile in the boundary layer thickness (less than $1 \mathrm{~mm}$ ) on small blades, the computed boundary layer displacement thicknesses obtained from numerical simulations of the baseline cases are used here.

Depicted in Figure 15a are the three cases with different riblet start locations on the blade and the three cases with different riblet heights. Since the case with $l_{L E}=0.5 \mathrm{c}$ and $h=0.0027 \mathrm{c}$ is shared among the 
cases with different riblet start locations and different riblet heights, the total number of cases is actually five. Figure 15a, the dark (red) circles denote the cases where loss reduction is not observed whereas the light (green) circles denote where a loss reduction is observed. In a given test series in which the riblet height and start position are fixed, $h / \delta^{*}$ displays a rising trend as expected because the local boundary layer thickness reduces as the Reynolds number increases. The critical Reynolds numbers in a given test series hence correspond to the minimum Reynolds number at which a loss reduction is first observed as the Reynolds number increases.

It is worth noting that due to the way in which the riblets were made in this study, the same base thickness of $0.0007 \mathrm{c}$ is left underneath riblets of different heights. As such, the actual location of the tips of riblets is $0.0007 \mathrm{c}$ further into the local boundary layer than the respective riblet height and in fact it should be equal to the thickness of the riblet foil itself. For completeness, the variations of $h_{r} / \delta^{*}$ with the Reynolds numbers for the same cases included in Figure 15a are also presented in Figure 15b.

The best fitted curve, which links the data points at the critical Reynolds numbers for all the cases presented in Figure 15a and 16b respectively, takes the form of:

$$
\begin{aligned}
& \frac{h}{\delta^{*}}=3 e^{-2.01 \times 10^{-5} \mathrm{Re}} \\
& \frac{h_{r}}{\delta^{*}}=3.5 e^{-1.64 \times 10^{-5} \mathrm{Re}}
\end{aligned}
$$

The above relationships show that the minimum value of $h / \delta^{*}$ and $h_{r} / \delta^{*}$ to guarantee a control effect is around 1.1 and 1.6, respectively, at a Reynolds number of $0.50 \times 10^{5}$. Despite the difference in the exact expressions for $h / \delta^{*}$ and $h_{r} / \delta^{*}$ as a function of critical Reynolds number, they both reduce exponentially with the Reynolds number. It should be noted that Eq.5 is derived for the test cases investigated in this study and hence the exact formula cannot be generalised. However, they do provide some insights into how the riblet geometry and start position of the riblet strips could be chosen to ensure an effective control of 2D flow separation around the mid-span of blades operating at low Reynolds numbers. Based on this correlation, a reduced riblet height is required (in order to be effective) as Re increases since the boundary layer is thinner. The same tends applies as the blade loading increases.

To select the riblet geometry and start position for a given blade and test condition, the following design procedure could be followed: Firstly, the location of flow separation on the blade surface is determined via CFD simulations. The start location of the riblet foils is then chosen to be around 0.1c upstream of the separation line in the baseline case as a further shift upstream will compromise the gain in loss reduction. Once the start location of the riblets is decided, the required riblet height can be determined by referencing Eq.5. Finally, as a compromise between creating a strong secondary flow motion and minimising the parasitic drag, the riblet spacing can be decided to ensure the highest $h / s$ ratio (possibly between 3 and 4 ) at which they can be treated as $d$-type roughness.

a)

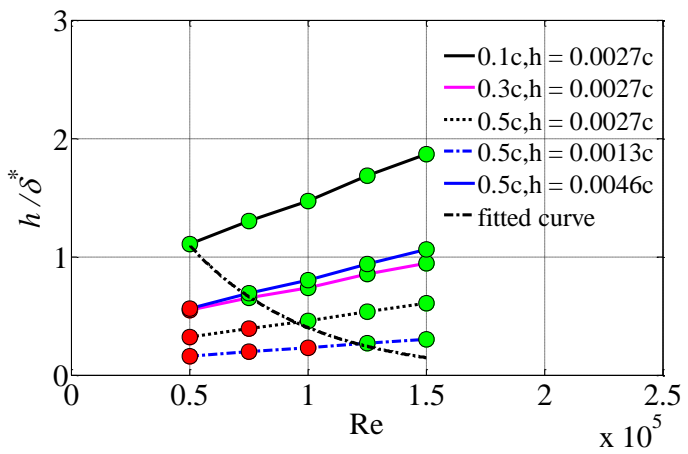

b)

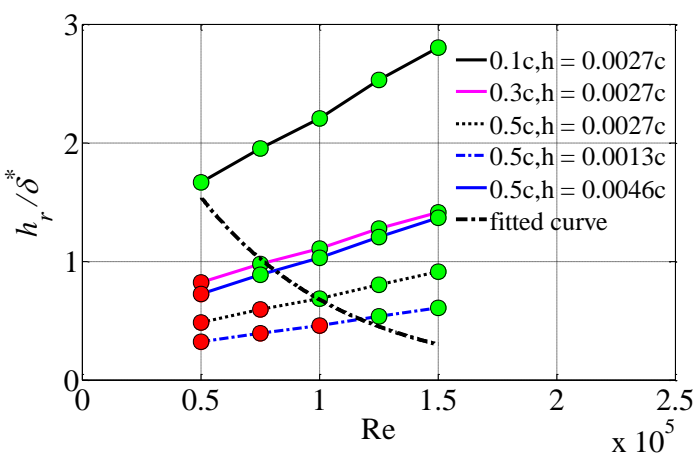

Figure 15 Variations of a) $h / \delta^{*}$ and b) $h_{r} / \delta^{*}$ with Reynolds numbers in different test cases. The fitted curve is the best fitted line that indicates the conditions at which herringbone riblets start to reduce the pressure losses. 


\section{Summary and Conclusions}

In this paper, the effects of an array of herringbone riblets with different riblet geometry (height and spacing) and start positions on the performance of diffuser blades are investigated in a linear cascade over a range of low Reynolds numbers $\left(0.50 \times 10^{5}-1.50 \times 10^{5}\right)$. A small five-hole probe was traversed across an exit plane downstream of the cascade to produce the flow field data from which pressure losses and flow turning angles were deduced.

The herringbone riblets tested in this experiment are found to produce a profound modification to the wake structure above certain critical Reynolds numbers. The observed modification is manifested by a narrowed width and a shift in location of the wake along with the appearance of a serrated wake structure. A narrowed wake width together with a shift in wake location towards the blade suction surface can be taken as evidence of a reduced extent of flow separation zone on the blade suction surface. The serrated wake structure is believed to be caused by the interaction of the secondary flow induced by the riblets with the separated flow over the blade surface. A considerable reduction in zone-averaged loss coefficient up to $39.5 \%$ and an increase in zone-averaged flow turning angle up to $4.1^{\circ}$ have been obtained.

Within the range of parameters tested, an increase in the riblet height and spacing leads to the onset of the tangential shift of the wake structure at lower Reynolds number. This onset marks a significant reduction in loss coefficient, accompanied by increased flow turning after which there is little or no improvement as the Reynolds number increases. On the start location of the riblets, a shift upstream from $0.5 \mathrm{c}$ also enables the riblets to be effective in reducing the loss coefficient only at lower Re.

Semi-empirical relationships between the ratio of riblet height to local baseline boundary layer displacement thickness and the critical Re were also established. It clearly shows that for the blades examined in this study, the minimum ratio to ensure a desired control effect is around 1 unity at a Reynolds number of $0.50 \times 10^{5}$ and it reduces exponentially as the Reynolds number increases. A preliminary methodology for designing the geometry and start location of herringbone riblets to ensure an effective control of 2D flow separations around the mid-span of diffuser blades over a specified range of Reynolds numbers is also proposed.

\section{Acknowledgements}

The authors would like to acknowledge the Engineering and Physical Sciences Research Council (EPSRC) in the UK and Dyson Technology Ltd for their financial support for this work. Our particular thanks also go to the aero acoustic team at Dyson Technology Ltd for many useful discussions.

\section{Nomenclature}

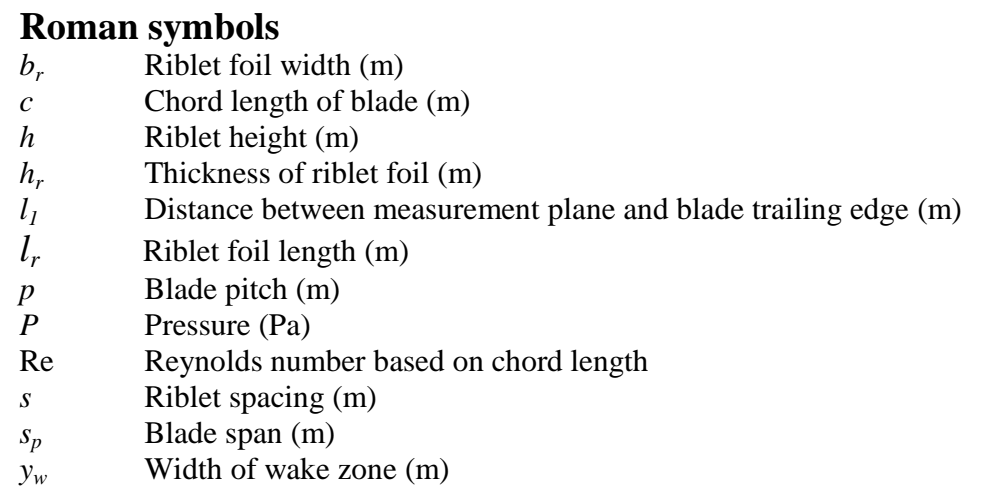

\section{Greek symbols}

$\alpha \quad$ Incidence angle $\left({ }^{\circ}\right)$

$\beta \quad$ Blade turning angle $\left({ }^{\circ}\right)$

$\beta_{1} \quad$ Inlet blade angle $\left({ }^{\circ}\right)$

$\beta_{2} \quad$ Exit blade angle $\left({ }^{\circ}\right)$ 


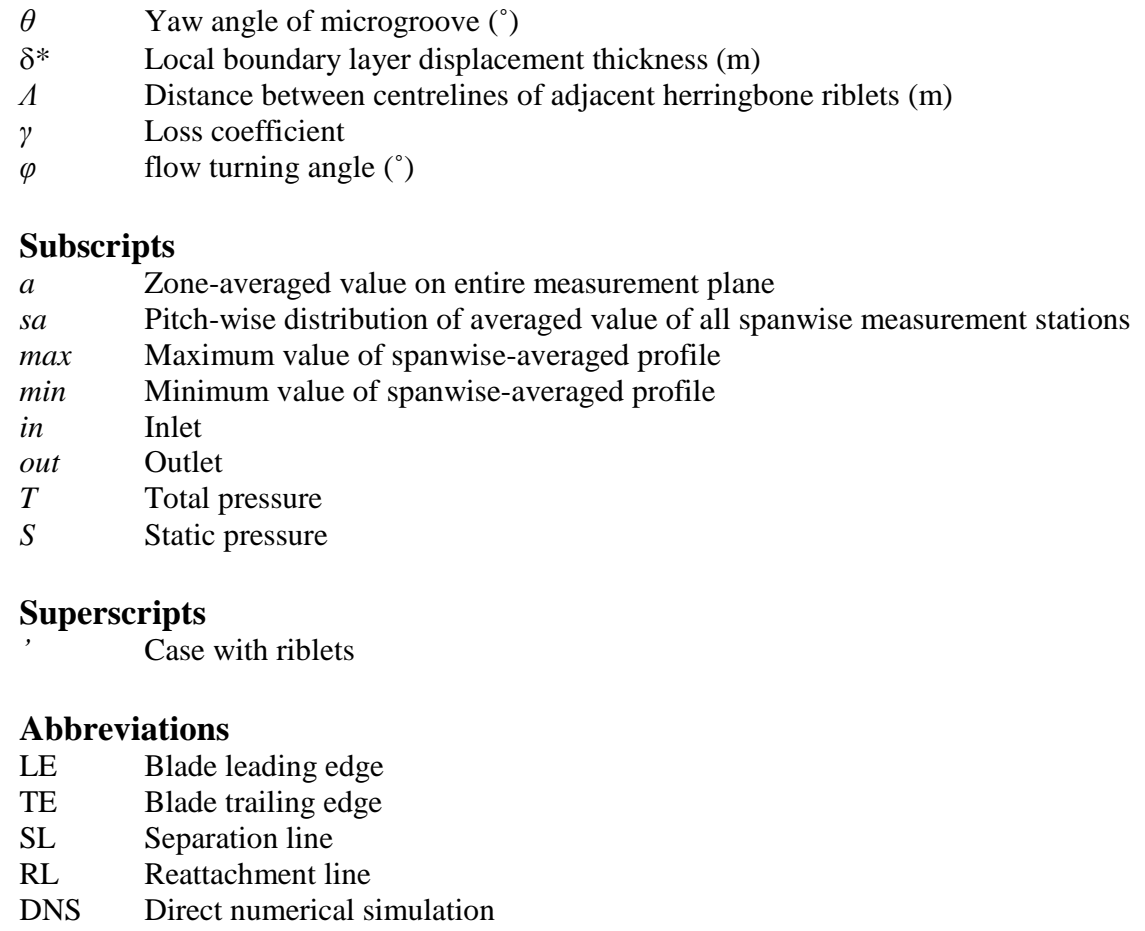

\section{Reference}

[1] Gad-el-Hak, M., 2007, "Flow control: passive, active, and reactive flow management", Cambridge university press.

[2] Zhang, S., and Zhong, S., 2010, "Experimental investigation of flow separation control using an array of synthetic jets," AIAA Journal, 48(3), pp. 611-623.

[3] Quan, P., Zhong, S., Liu, Q., and Li, L., 2018, "Attenuation of Flow Separation Using Herringbone Riblets at $\mathrm{M}_{\infty}=5$," AIAA Journal, 57(1), pp. 142-152.

[4] Nerger, D., Saathoff, H., Radespiel, R., Gümmer, V., and Clemen, C., 2012, "Experimental Investigation of Endwall and Suction Side Blowing in a Highly Loaded Compressor Stator Cascade," Journal of Turbomachinery, 134(2), p. 021010.

[5] Huang, J., Corke, T. C., and Thomas, F. O., 2006, "Plasma Actuators for Separation Control of Low-Pressure Turbine Blades," AIAA Journal, 44(1), pp. 51-57.

[6] Şahin, F. C., 2017, "Experimental investigation on flow improvement in compressor cascades," International Journal of Energy Research, 41(4), pp.526-539.

[7] Mueller, T. J., and Batil, S. M., 1982, "Experimental Studies of Separation on a Two-Dimensional Airfoil at Low Reynolds Numbers," AIAA Journal, 20(4), pp. 457-463.

[8] Bons, J. P., 2010, "A Review of Surface Roughness Effects in Gas Turbines," Journal of Turbomachinery, 132(2), p. 021004.

[9] Evans, C. J., and Bryan, J. B., 1999, "Structured, Textured or Engineered Surfaces," CIRP Annals, 48(2), pp. 541-556.

[10] Zhang, X., Zhang, D. Y., Pan, J. F., Li, X., and Chen, H. W., 2013, "Controllable Adjustment of Bio-Replicated Shark Skin Drag Reduction Riblets," Applied Mechanics and Materials, 461, pp. 677680.

[11] Walsh, M. J., 1983, "Riblets as a viscous drag reduction technique," AIAA Journal, 21(4), pp. 485-486.

[12] Lietmeyer, C., Oehlert, K., and Seume, J. R., 2012, "Optimal Application of Riblets on Compressor Blades and Their Contamination Behavior," Journal of Turbomachinery, 135(1), p. 011036.

[13] Chen, H. W., Rao, F. G., Zhang, D. Y., and Shang, X. P., 2013, "Drag Reduction Study about Bird Feather Herringbone Riblets," Applied Mechanics and Materials, 461, pp. 201-205.

[14] Chen, H., Rao, F., Shang, X., Zhang, D., and Hagiwara, I., 2014, "Flow over bio-inspired 3D herringbone wall riblets," Experiments in Fluids, 55(3). 
[15] Xu, F., Zhong, S., and Zhang, S., 2018, "Vortical structures and development of laminar flow over convergent-divergent riblets," Physics of Fluids, 30(5), p. 051901.

[16] Kevin, K., Monty, J. P., Bai, H. L., Pathikonda, G., Nugroho, B., Barros, J. M., Christensen, K. T., and Hutchins, N., 2017, "Cross-stream stereoscopic particle image velocimetry of a modified turbulent boundary layer over directional surface pattern," Journal of Fluid Mechanics, 813, pp. 412-435.

[17] Xu, F., Zhong, S., and Zhang, S., 2019, "Statistical analysis of vortical structures in turbulent boundary layer over directional grooved surface pattern with spanwise heterogeneity," Physics of Fluids, 31(8), p. 085110.

[18] Benschop, H., and Breugem, W.-P., 2017, "Drag reduction by herringbone riblet texture in direct numerical simulations of turbulent channel flow," Journal of Turbulence, 18(8), pp.717-759.

[19] Liu, Q., Zhong, S., and Li, L., "Reduction of Pressure Losses in a Linear Cascade Using Herringbone Riblets," Proc. ASME Turbo Expo 2017: Turbomachinery Technical Conference and Exposition, American Society of Mechanical Engineers, pp. V02AT39A025-V002AT039A025.

[20] Liu, Q., Zhong, S., and Li, L., 2019, "Effects of Bio-inspired Micro-scale Surface Patterns on the Profile Losses in a Linear Cascade," Journal of Turbomachinery, 141(12): 121006.

[21] Dixon, S. L., and Hall, C., 2013, Fluid mechanics and thermodynamics of turbomachinery, Butterworth-Heinemann.

[22] Dominy, R., and Hodson, H., "An investigation of factors influencing the calibration of 5-hole probes for 3-D flow measurements," Proc. ASME 1992 International Gas Turbine and Aeroengine Congress and Exposition, American Society of Mechanical Engineers, pp. V001T001A077V001T001A077.

[23] Roberts, W., 1975, "The effect of Reynolds number and laminar separation on axial cascade performance," Journal of Engineering for Power, 97(2), pp. 261-273.

[24] Wang, S., Zhou, Y., Alam, M. M., and Yang, H., 2014, "Turbulent intensity and Reynolds number effects on an airfoil at low Reynolds numbers," Physics of Fluids, 26(11), p. 115107.

[25] Langtry, R. B., and Menter, F. R., 2009, "Correlation-based transition modeling for unstructured parallelized computational fluid dynamics codes," AIAA Journal, 47(12), pp. 2894-2906.

[26] Perry, A. E., Schofield, W. H., and Joubert, P. N., 1969, "Rough wall turbulent boundary layers," Journal of Fluid Mechanics, 37(2), pp. 383-413. 